\title{
Summer Water Vapor Sources in Northeast Asia and East Siberia Revealed by a Moisture-Tracing Atmospheric Model
}

\author{
JINLING PIAO \\ Center for Monsoon System Research, Institute of Atmospheric Physics, Chinese Academy of Sciences, Beijing, China \\ Wen CHEN AND SHANGFEng CHEN \\ Center for Monsoon System Research, Institute of Atmospheric Physics, Chinese Academy of Sciences, and College of Earth \\ and Planetary Sciences, University of Chinese Academy of Sciences, Beijing, China \\ HAINAN GONG \\ Center for Monsoon System Research, Institute of Atmospheric Physics, Chinese Academy of Sciences, Beijing, China \\ QIONG ZHANG \\ Department of Physical Geography, and Bolin Centre for Climate Research, Stockholm University, Stockholm, Sweden
}

(Manuscript received 10 July 2019, in final form 23 January 2020)

\begin{abstract}
Previous studies found a seesaw pattern of summer precipitation between northeast Asia and east Siberia on an interannual time scale, which is associated with an eastward-propagating atmospheric wave train over Eurasia and corresponding water vapor transport circulations. Using a general circulation model with an embedded water-tagging module, the main water vapor sources of the two regions, as well as the relative contributions of each source region to the total precipitation for both the climatological mean and interdecadal variation, are further compared in this study. The model simulation results show that local evaporation, the Pacific Ocean, and East Asia are the dominant moisture sources for northeast Asian precipitation. In contrast, for east Siberia, moisture mainly originates from the Pacific Ocean, northeast Asia, west Siberia, and local evaporation. This suggests that the local evaporation and Pacific Ocean are both crucial to the moisture supply of the two regions, implying the important roles of the land processes and adjacent oceanic sources. In addition, northeast Asia appears to be the major moisture source for east Siberia, whereas east Siberia has weak impacts on the moisture input for northeast Asia. Further analysis finds that the model simulation can capture interdecadal changes in summer precipitation over the two regions around the late 1990s. This interdecadal change is mainly manifested in the moisture supplies from the Pacific Ocean, North Atlantic Ocean, and east Siberia, which suggests a link with the circulation anomalies under the combined impacts of the Pacific decadal oscillation and the Atlantic multidecadal oscillation.
\end{abstract}

\section{Introduction}

Eastern Eurasia stretches across the mid- to high latitudes, mainly covering northeast Asia and the eastern part of Siberia. The annual total precipitation amount in this location ranges from less than $200 \mathrm{~mm}$ in southeastern Mongolia to more than $800 \mathrm{~mm}$ over the western coast of the Okhotsk Sea, including arid, semiarid, semihumid, and humid climate zones. Corresponding to

Corresponding author: Wen Chen, cw@post.iap.ac.cn the various climate zones, a wide range of ecosystems exist within this region, such as deserts, grasslands, farmlands, and forests. In particular, the transition areas of different climate zones are very sensitive to climate change. Among all the climate variables, precipitation change is one of the most important factors that can exert significant impacts on the agricultural yields, ecological balance, and economic growth (Chuai et al. 2013; Munkhtsetseg et al. 2007; Park et al. 2010). The precipitation variation here is very complex under the control of atmospheric circulations from the low and 
mid-high latitudes. Hence, much work has been devoted to investigating the physical mechanisms of precipitation change from the perspective of extreme events (Khon et al. 2007; Wang and He 2015; Wang et al. 2017), long-term trends (Endo et al. 2006; Fujinami et al. 2016; Zhu et al. 2012), and interannual (Ding and Wang 2005; Hiyama et al. 2016; Lee et al. 2005; Zhao et al. 2019) and interdecadal variations (Chen et al. 2009, 2013; Han et al. 2015; Ho et al. 2003).

In addition to the abovementioned studies, other research has been carried out to investigate the hydrological characteristics of this region to obtain a better understanding of the precipitation variation features, with a main focus on the water vapor budget and moisture origins (Numaguti 1999; Sun et al. 2007; Yatagai and Yasunari 1998; Ye et al. 2014). Thus far, it has been within the research hotpot of global climate change to understand the mechanisms behind water vapor that evaporates from oceanic sources along with its atmospheric transport and their connection with the hydrological cycle (Gimeno 2014; IPCC 2013; Trenberth et al. 2003; Yu and Weller 2007). The potential water vapor sources inferred by previous studies can be classified into two categories: the low-latitude and midhigh-latitude regions. The low-latitude sources consist of the East Asian summer monsoon regions and oceans southeast of the Asian continent, including the South China Sea, East China Sea, and subtropical Pacific (Sun et al. 2007; Zhou and Yu 2005). Sun et al. (2007) suggested that the northward moisture transport dominated the summer precipitation change over Northeast China, which originated from the subtropical monsoon area, the South China Sea monsoon area and the South Asian monsoon area. The mid-high-latitude sources are considered to be the North Atlantic Ocean, central Asia, and the western part of Siberia (Numaguti 1999; Sato et al. 2007; Yatagai and Yasunari 1998; Zhang et al. 2013). Based on the analysis of vertically integrated water vapor transport, Yatagai and Yasunari (1998) demonstrated that western Siberia is one of the main water vapor sources for Mongolia and northern China. Numaguti (1999) showed that the north Indian Ocean, northwest Pacific Ocean, and North Atlantic Ocean are the main moisture sources for the Eurasian continent. Clearly, discrepancies exist among various studies on water vapor sources, which may be due to differences in research periods, employed datasets, and adopted methods.

Thus far, a number of methods have been employed in moisture source investigations, such as studies on the composition of water isotopes (Sato et al. 2007) and methods based on the Lagrangian (Sun et al. 2010) and Eulerian frameworks (Fukutomi et al. 2003). The water isotope analysis mainly applies the isotope ratios in precipitation and water vapor to trace water vapor origins, with a limitation related to the lack of observed isotope data. For the Lagrangian method, the specific trajectories of the targeted moisture parcels are traced backward to quantitatively describe the transport process, which can provide a direct relationship between the source and receptor. However, the method is disadvantageous in association with the upper limitation of how far into the past the parcels can be traced due to inevitable interpolation errors that grow over time (Bowman et al. 2013). The conventional Eulerian method identifies moisture sources from the vertically integrated moisture input across regional boundaries, failing to provide the source-receptor relationship. For an improvement, several studies adopted atmospheric moisture tracking model to obtain the information about distribution of the moisture origin under the Eulerian frame (Bosilovich and Chern 2006; Bosilovich and Schubert 2002; Sodemann et al. 2009; Van der Ent and Savenije 2013; Zhang et al. 2019). Recently, Salih et al. (2016) utilized a technique known as water tagging to investigate the moisture source of Sahelian Sudan. This method traces the water vapor from the evaporation in the source region to its precipitation formation within the target region and is not limited by the tracing time of water vapor parcels. Following Salih et al. (2016), the water-tagging method is employed in this study to trace the moisture sources for the target region. The summer precipitation between northeast Asia and east Siberia presents a dominant seesaw pattern revealed by the empirical orthogonal function analysis (EOF), which is associated with the eastwardpropagating atmospheric Rossby wave train over the Eurasian continent (Iwao and Takahashi 2006, 2008). Then, Piao et al. (2018) compared the climatological water vapor budget and water vapor transport circulations related to the anomalous precipitation over the two regions based on the vertically integrated water vapor flux. Using the water-tagging method, it is attempted in this study to further identify their water vapor sources, particularly by examining the relative contributions of each source; the connections of water vapor sources with the interdecadal variations in the seesaw pattern of summer precipitation are also discussed.

\section{Data and methods}

The Community Atmospheric Model, version 3 (CAM3) (Collins et al. 2006), developed at the National Center for Atmospheric Research (NCAR) is applied in this study. For the dynamical core of CAM3, three options are available: spectral, finite volume, and semiLagrangian. Because our aim is to trace water vapor 
transport, the finite-volume core (CAM-FV) is selected to gain the optimal mass and energy balance. The dynamical core and physical parameterization are completely separated in CAM-FV, and they are coupled in a time-split approximation (Collins et al. 2006; Lin 2004; Williamson 2002). The Community Land Model is used as the surface scheme in CAM3 (Dickinson et al. 2006). The prognostic parameterization used as the cloud water scheme was developed by Rasch and Kristjánsson (1998) and has since been updated by Zhang et al. (2003). The shallow and deep convective cloud fraction is represented by functions of convective updraft mass flux, as described in Xu and Krueger (1991).

In addition, a moisture-tagging module is included in CAM3, which has already been used to investigate the water vapor origins of the precipitation falling over South and East Asia (Pausata et al. 2011), the Antarctic (Noone and Simmonds 2002), and the Sahelian Sudan (Salih et al. 2016). In corporation of additional tracers for each source region, this module tags water vapor from the source region and tracks the vapor through the CAM3 hydrologic cycle until its fall as precipitation (Delaygue et al. 2000; Joussaume and Sadourny 1986; Koster et al. 1986; Werner et al. 2001). The model output provides the amount of the water vapor from each source region that turns into precipitation at each grid for each month, regardless of issues related to the residence time of the water vapor in the air (Numaguti 1999; Trenberth 1998). With this information, the main moisture sources for the target region can be distinguished. This tracking process is mainly accomplished by using the same model physics to both the tagged tracer water and the model's standard water prognostic variables. For more details of this method, they can be found in Joussaume and Sadourny (1986) and Koster et al. (1986). We carried out the model simulations following the protocol of the Atmospheric Model Intercomparison Project (AMIP1) (Gates et al. 1999) and used the prescribed sea surface temperature (SST) data from the Hadley Centre (Rayner et al. 2003) as boundary conditions. CAM3 has already been used for various climate studies and has proven to have a good ability to trace moisture transport and identify potential sources (Pausata et al. 2011; Salih et al. 2016).

The model simulation is a one-way run from 1979 to 2017 with a horizontal resolution of $2.8^{\circ} \times 2.8^{\circ}$. The model output has 26 levels in the vertical direction, with the top set at $3.5 \mathrm{hPa}$. Based on previous studies (Sato et al. 2007), 10 potential moisture sources are selected to account for the summer precipitation falling within northeast Asia and east Siberia. These 10 regions are located in northeast Asia, the northern Atlantic Ocean, west Siberia, east Siberia, central Asia, southwestern

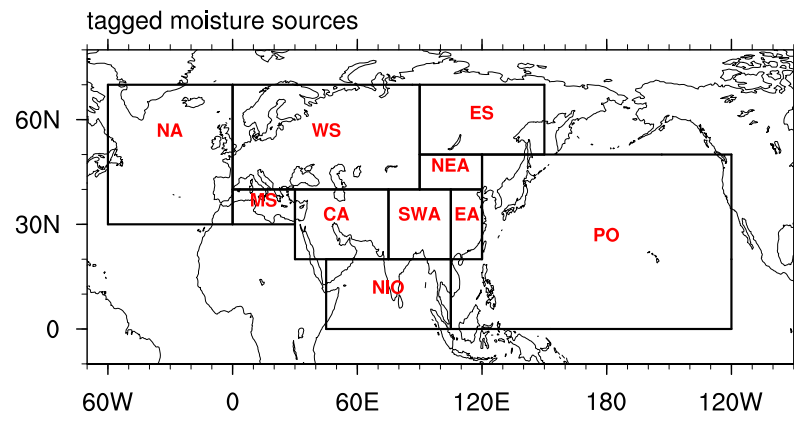

FIG. 1. The 10 selected moisture sources for northeast Asia and east Siberia and their geographical boundaries. NEA, northeast Asia; NA, the northern Atlantic Ocean; WS, west Siberia; ES, east Siberia; CA, central Asia; SWA, southwestern Asia; EA, East Asia; NIO, northern Indian Ocean; PO, Pacific Ocean; MS, the Mediterranean Sea. These abbreviations are also applied to Figs. 4-6 and Figs. 9-11.

Asia, East Asia, the northern Indian Ocean, the Pacific Ocean, and the Mediterranean Sea (Fig. 1 and Table 1). Northeast Asia and east Siberia are chosen to show the importance of the local evaporation on the summer precipitation within the two regions (Fukutomi et al. 2003; Piao et al. 2018). East Asia, the northern Indian Ocean, and the Pacific Ocean account for the precipitation related to the prevailing southerlies over East Asia (Sun et al. 2007; Zhou and Yu 2005). Central Asia, west Siberia, and southwestern Asia represent the contributions from the mid-high latitudes (Sato et al. 2007; Yatagai and Yasunari 1998). The North Atlantic Ocean and Mediterranean Sea are considered to be remote oceanic sources (Numaguti 1999). The contribution from the rest of the globe is calculated as the residual between the summer precipitation of the target region and the sum of the precipitation that originates from the 10 moisture sources. Notably, our selection of potential moisture sources is similar to that in Sato et al. (2007).

The model output is then evaluated from the performance of precipitation, evaporation and accompanied atmospheric circulations. The monthly observational precipitation data are extracted from the Global Precipitation Climatology Project (GPCP), version 2.3, with a horizontal resolution of $2.5^{\circ} \times 2.5^{\circ}$, and span from 1979 to the present (Adler et al. 2003). The monthly atmospheric fields are provided by the European Centre for Medium-Range Weather Forecasts (ECMWF) Interim Reanalysis (ERA-Interim) (Dee et al. 2011), with a horizontal resolution of $2.5^{\circ} \times 2.5^{\circ}$ (latitudelongitude), spanning from 1979 to 2017 . The monthly evaporation data for the ocean are obtained from the Woods Hole Oceanographic Institution (WHOI) objectively analyzed air-sea heat fluxes (OAFlux) dataset (Yu and Weller 2007), spanning from 1958 to the present on a $1^{\circ} \times 1^{\circ}$ grid, and the data for land are taken from the 
TABLE 1 . The 10 selected moisture sources and the corresponding geographical information.

\begin{tabular}{lcc}
\hline \hline \multicolumn{1}{c}{ Moisture sources } & Latitude & Longitude \\
\hline Northeast Asia & $40^{\circ}-50^{\circ} \mathrm{N}$ & $90^{\circ}-120^{\circ} \mathrm{E}$ \\
Northern Atlantic Ocean & $30^{\circ}-70^{\circ} \mathrm{N}$ & $60^{\circ} \mathrm{W}-0^{\circ} \mathrm{E}$ \\
West Siberia & $40^{\circ}-70^{\circ} \mathrm{N}$ & $0^{\circ}-90^{\circ} \mathrm{E}$ \\
East Siberia & $50^{\circ}-70^{\circ} \mathrm{N}$ & $90^{\circ}-150^{\circ} \mathrm{E}$ \\
Central Asia & $20^{\circ}-40^{\circ} \mathrm{N}$ & $30^{\circ}-75^{\circ} \mathrm{E}$ \\
Southwestern Asia & $20^{\circ}-40^{\circ} \mathrm{N}$ & $75^{\circ}-105^{\circ} \mathrm{E}$ \\
East Asia & $20^{\circ}-40^{\circ} \mathrm{N}$ & $105^{\circ}-120^{\circ} \mathrm{E}$ \\
Northern Indian Ocean & $0^{\circ}-20^{\circ} \mathrm{N}$ & $45^{\circ}-105^{\circ} \mathrm{E}$ \\
Pacific Ocean & $0^{\circ}-20^{\circ} \mathrm{N} / 20^{\circ}-50^{\circ} \mathrm{N}$ & $105^{\circ}-240^{\circ} \mathrm{E} / 120^{\circ}-240^{\circ} \mathrm{E}$ \\
Mediterranean Sea & $30^{\circ}-40^{\circ} \mathrm{N}$ & $0^{\circ}-30^{\circ} \mathrm{E}$ \\
\hline
\end{tabular}

Noah model in the Global Land Data Assimilation System (GLDAS) (Rodell et al. 2004), which is available from 1979 to the present at a $1^{\circ}$ spatial resolution.

Following Trenberth (1991), the vertically integrated water vapor flux $\mathbf{Q}$ can be expressed as

$$
\mathbf{Q}=-\frac{1}{g} \int_{p_{\text {surf }}}^{200} q \mathbf{V} d p,
$$

where $g, q$, and $p_{\text {surf }}$ indicate the acceleration of gravity, specific humidity, and surface pressure, respectively; $\mathbf{V}$ is the horizontal wind vector. Besides, the anomaly of the water vapor flux can be calculated as

$$
\begin{aligned}
\mathbf{Q}^{\prime}= & \mathbf{Q}-\overline{\mathbf{Q}} \\
= & -\frac{1}{g} \int_{p_{\text {surf }}}^{200}\left(\overline{\mathbf{V}}+\mathbf{V}^{\prime}\right)\left(\bar{q}+q^{\prime}\right) d p \\
& +\frac{1}{g} \int_{p_{\text {surf }}}^{200} \frac{\left(\overline{\mathbf{V}}+\mathbf{V}^{\prime}\right)\left(\bar{q}+q^{\prime}\right)}{d p} \\
= & -\frac{1}{g} \int_{p_{\text {surf }}}^{200} \overline{\mathbf{V}} q^{\prime} d p-\frac{1}{g} \int_{p_{\text {surf }}}^{200} \mathbf{V}^{\prime} \bar{q} d p \\
& -\frac{1}{g} \int_{p_{\text {surf }}}^{200}\left(\mathbf{V}^{\prime} q^{\prime}-\overline{\mathbf{V}^{\prime} q^{\prime}}\right) d p,
\end{aligned}
$$

where the overbar and prime are representative of the time average and anomaly, respectively. On the right side, the first term stands for the disturbance moisture transported by the mean wind $\mathbf{Q}_{\text {moisture }}^{\prime}$, with the second for the mean moisture transported by the disturbance wind $\mathbf{Q}_{\text {wind }}^{\prime}$, and the third on behalf of the disturbance moisture transported by the disturbance wind.

\section{Results}

\section{a. Model evaluation}

As a starting point, the performance of the model is evaluated against the observations and reanalysis in regard to the precipitation, evaporation, and atmospheric circulations. The model can generally reproduce the climatological distribution of the summer precipitation and evaporation over northeast Asia and east Siberia (Fig. 2), with larger amounts in the south (east) than in the north (west) in east Siberia (northeast Asia) for both of the two fields. In the precipitation field, excessive amounts spread over northeast Asia and east Siberia in the model results compared to the results derived from GPCP (Figs. 2a,d). Based on the differences between CAM3 and GPCP (figure not shown), the model tends to overestimate the precipitation over most parts of east Siberia with an amplitude ranging from 0 to $10 \mathrm{~mm} \mathrm{month}^{-1}$ and from 10 to $40 \mathrm{~mm} \mathrm{month}^{-1}$ along the eastern edge of this area. For northeast Asia, the model overestimation is more significant and ranges from 0 to $10 \mathrm{~mm} \mathrm{month}^{-1}$ in the northwest and from 40 to $50 \mathrm{~mm} \mathrm{month}^{-1}$ in the southeast. In accompaniment, a positive evaporative bias occupies both northeast Asia and east Siberia (Figs. 2b,e), most of which ranges from 0 to $90 \mathrm{~mm} \mathrm{month}^{-1}$ except for those larger than $120 \mathrm{~mm} \mathrm{month}^{-1}$ in the southeast of northeast Asia (figure not shown). It should be noted that large discrepancies exist over eastern China (Figs. 2b,e), indicating the model's limited performance on the evaporation over this area. Consistent with the overestimation of precipitation amount, the atmospheric circulations are also characterized by a stronger intensity in the model output compared to those in the ERAInterim (Fig. 3). The model produces a strengthened westerly at mid-high latitudes in both high and low levels (Figs. 3b,d), with the strengthening more apparent in the low level (Fig. 3d). In accompany, the prevailing southerly over East Asia is also enhanced in the low level (Fig. 3d). Though these discrepancies, the model can capture the main controlling atmospheric systems, such as the westerly jet and East Asian summer monsoon.

To further test the reliability of the model simulations, annual cycles of precipitation over northeast Asia and east Siberia are further compared between the model output and observation. The GPCP precipitation 
(a) GPCP precip

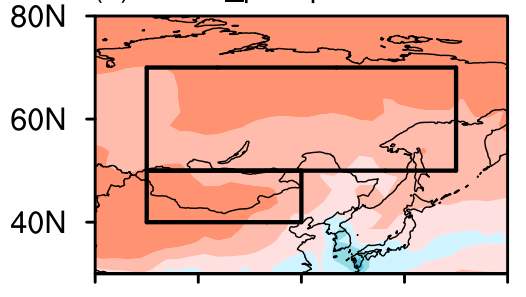

80E $\quad 100 \mathrm{E} \quad 120 \mathrm{E} \quad 140 \mathrm{E} \quad 160 \mathrm{E}$ (d) CAM3 precip

$80 \mathrm{~N}$
$60 \mathrm{~N}$
$40 \mathrm{~N}$ (b) GLDAS_evaporation

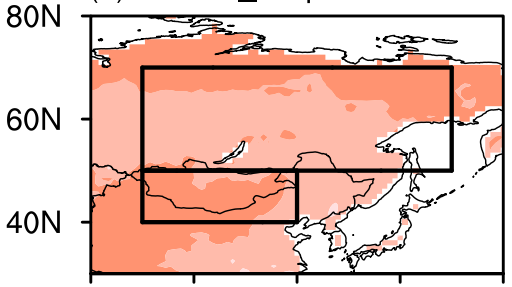

(c) OAFLUX evaporation

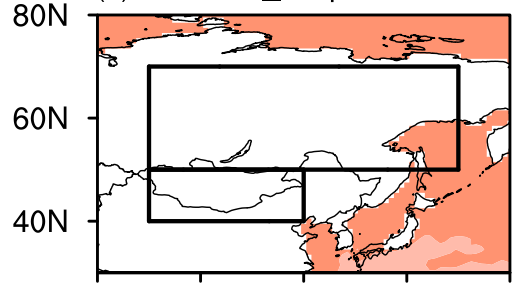

80E $100 \mathrm{E} \quad 120 \mathrm{E} \quad 140 \mathrm{E} \quad 160 \mathrm{E} \quad 80 \mathrm{E} \quad 100 \mathrm{E} \quad 120 \mathrm{E} \quad 140 \mathrm{E} \quad 160 \mathrm{E}$ (e) CAM3_evaporation

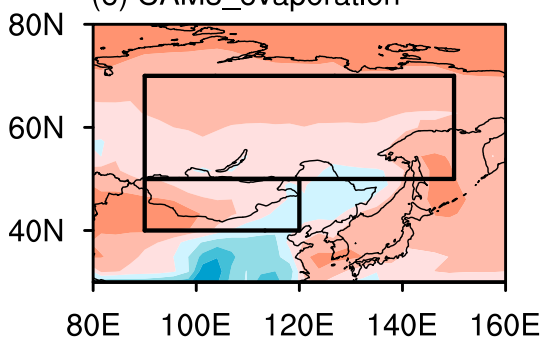

$80 \mathrm{E} \quad 100 \mathrm{E} \quad 120 \mathrm{E} \quad 140 \mathrm{E} \quad 160 \mathrm{E} \quad 80 \mathrm{E} \quad 100 \mathrm{E} \quad 120 \mathrm{E} \quad 140 \mathrm{E} \quad 160 \mathrm{E}$

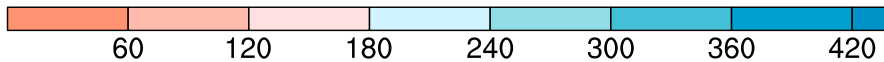

FIG. 2. Spatial distribution of the climatological summer (June-August mean) precipitation (mm month ${ }^{-1}$ ) from (a) GPCP and (d) CAM3, and evaporation from (b) GLDAS, (c) OAFLUX, and (e) CAM3 (mm month ${ }^{-1}$ ) during 1979-2017. The upper and lower black boxes represent the defined areas for east Siberia and northeast Asia, respectively.

amount over northeast Asia is relatively low (less than $20 \mathrm{~mm} \mathrm{month}^{-1}$ ) in spring but increases sharply after May and reaches its maximum in July and August (more than $60 \mathrm{~mm}$ month $\left.^{-1}\right)$. After August, the precipitation amount shows a significant decrease, and the minimum occurs in winter (Fig. 4a). Compared to the GPCP results, the model simulates a larger precipitation amount throughout a year, especially in the first half of the year, (a) ERA

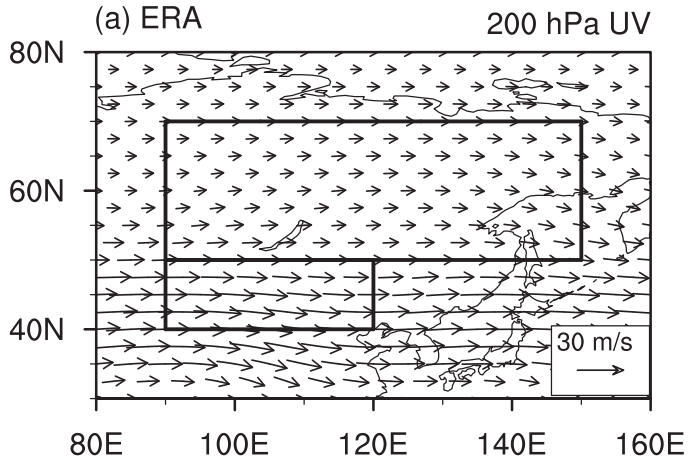

(c) ERA

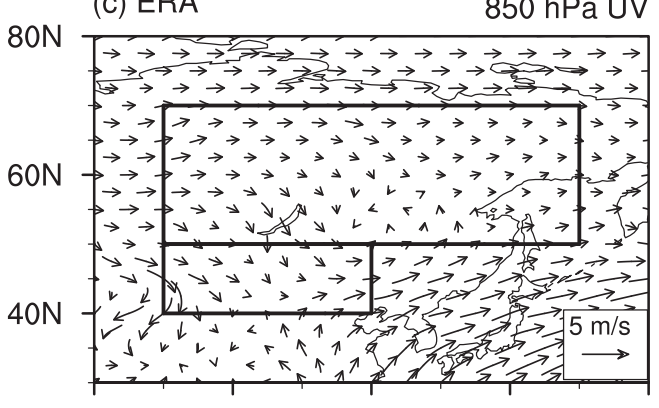

(b) $\mathrm{CAM} 3$

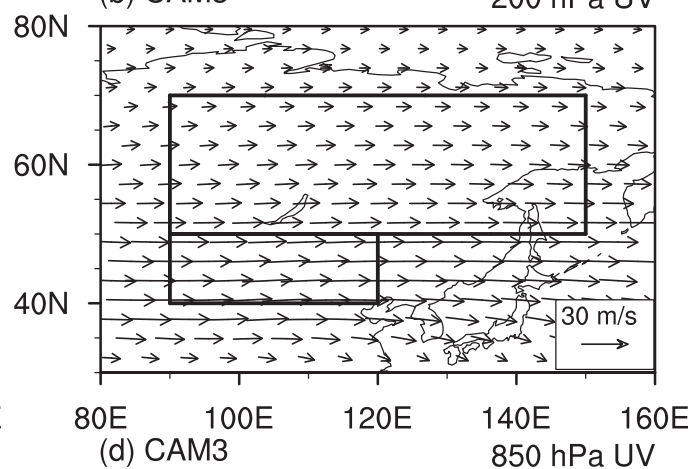

$80 \mathrm{~N}$

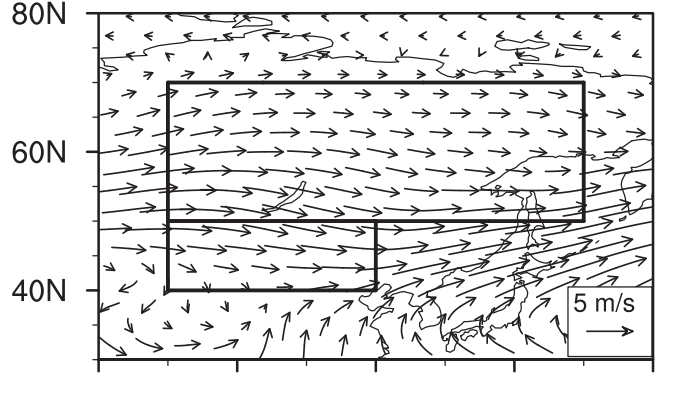

80E 100E 120E 140E 160E

FIG. 3. Spatial distribution of climatological horizontal winds $\left(\mathrm{m} \mathrm{s}^{-1}\right)$ in summer at (a) 200 and (c) $850 \mathrm{hPa}$ obtained from ERA-Interim during 1979-2017. (b),(d) As in (a) and (c), but for the results derived from CAM3. 

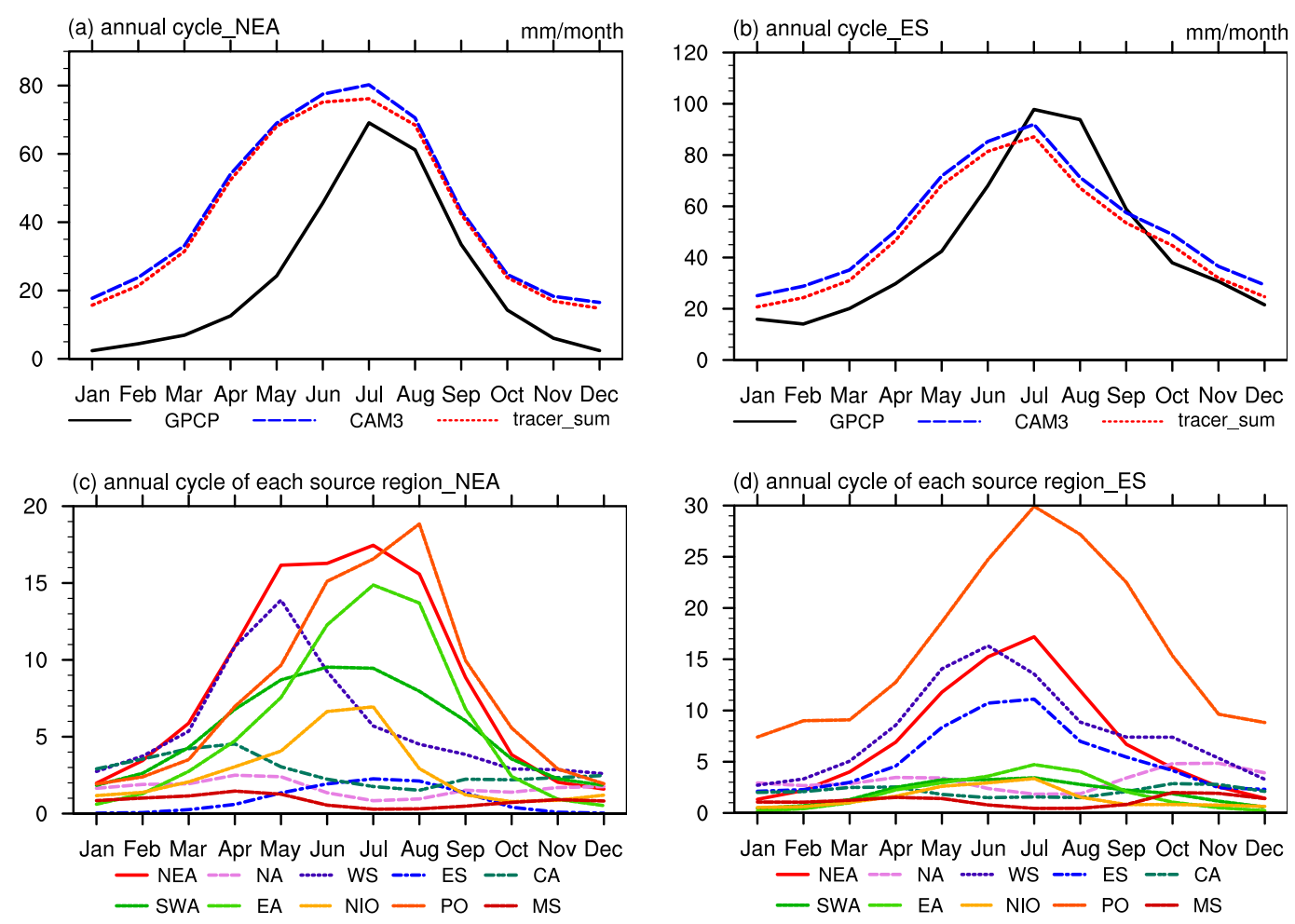

FIG. 4. Annual cycle of the area mean precipitation $\left(\mathrm{mm} \mathrm{month}^{-1}\right)$ based on GPCP (solid black line), CAM3 (dotted blue line), and the sum of the precipitation that originates from the 10 moisture sources (dotted red line) over (a) northeast Asia and (b) east Siberia, and the contributions from the 10 selected moisture source regions to the precipitation over (c) northeast Asia and (d) east Siberia.

which is consistent with the results obtained from Fig. 2. After June, the time series of the GPCP and model simulations varies in phase with each other (Fig. 4a). Although the precipitation amount is overestimated in Fig. 2, the model accurately reproduces the precipitation maximum for July and the annual cycle. The annual precipitation cycle over east Siberia resembles that over northeast Asia, but with more precipitation for most of the year (Fig. 4b). The CAM3 output underestimates the precipitation amount over east Siberia from July to September but overestimates it during other months, with the GPCP precipitation maximum observed in July (Fig. 4b). In general, the model simulations agree well with the observations for the annual cycle over northeast Asia and east Siberia.

We further examine the annual cycle of the precipitation that originates from each source region for the two regions (Figs. 4c,d). Over northeast Asia, the precipitation from East Asia has the most similar annual cycle to that of the observed and simulated precipitation, with the peak shown in July. The water vapor from the Pacific Ocean and local evaporation both play an important role in the total summer precipitation, while the former delays the precipitation maxima until August and the latter overestimates the precipitation in the early summer. Before May, the water vapor contribution from west Siberia is comparable to that of the local evaporation but decreases rapidly due to the weakening of the midlatitude westerly (Fig. 4c). For the situation over east Siberia, the water vapor from the Pacific Ocean, northeast Asia, local evaporation, and west Siberia exhibits a similar annual cycle to that of the total summer precipitation (Fig. 4d). The former three show the precipitation maximum in July, but the last one advances the maximum to June, which may be induced by the weakening of the westerly (Fig. 4d). Notably, the annual cycle of the precipitation sum from the 10 selected sources is nearly identical to that of the simulated summer precipitation over the two target regions (Figs. 4a,b). The above results collectively confirm the reliability of employing the CAM3 model simulations to investigate the moisture origins over east Siberia and northeast Asia.

\section{b. The main moisture source for northeast Asia and east Siberia}

In this section, we quantify the relative contributions of 10 selected source regions for the summer precipitation over east Siberia and northeast Asia. The Pacific Ocean, local evaporation, and East Asia are the three 
(a) cotribution from each source region NEA
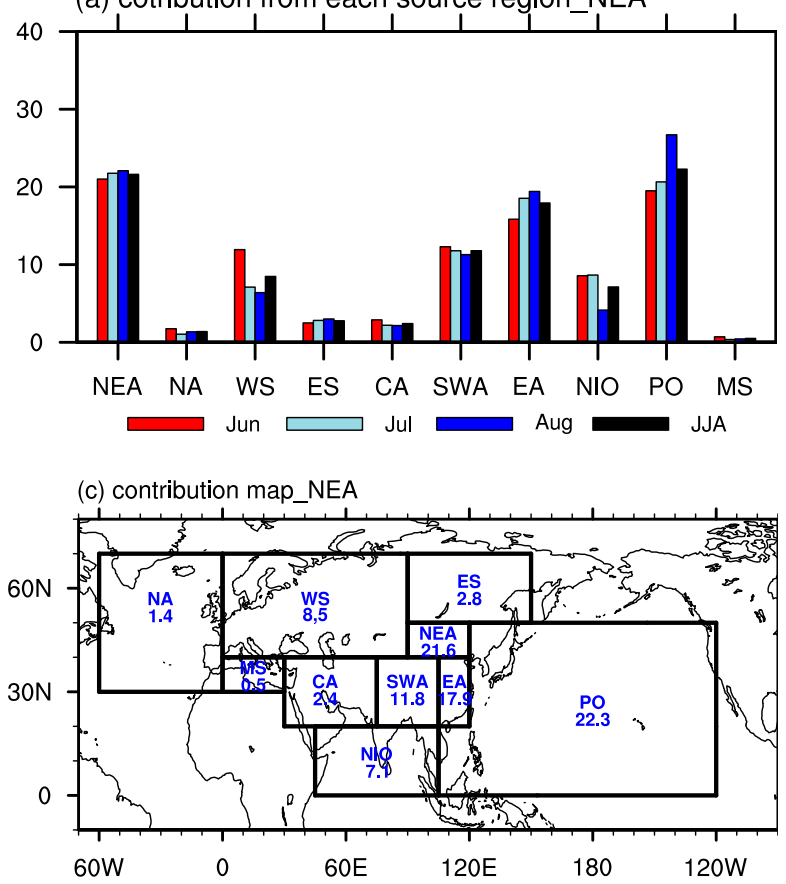

(b) cotribution from each source region ES
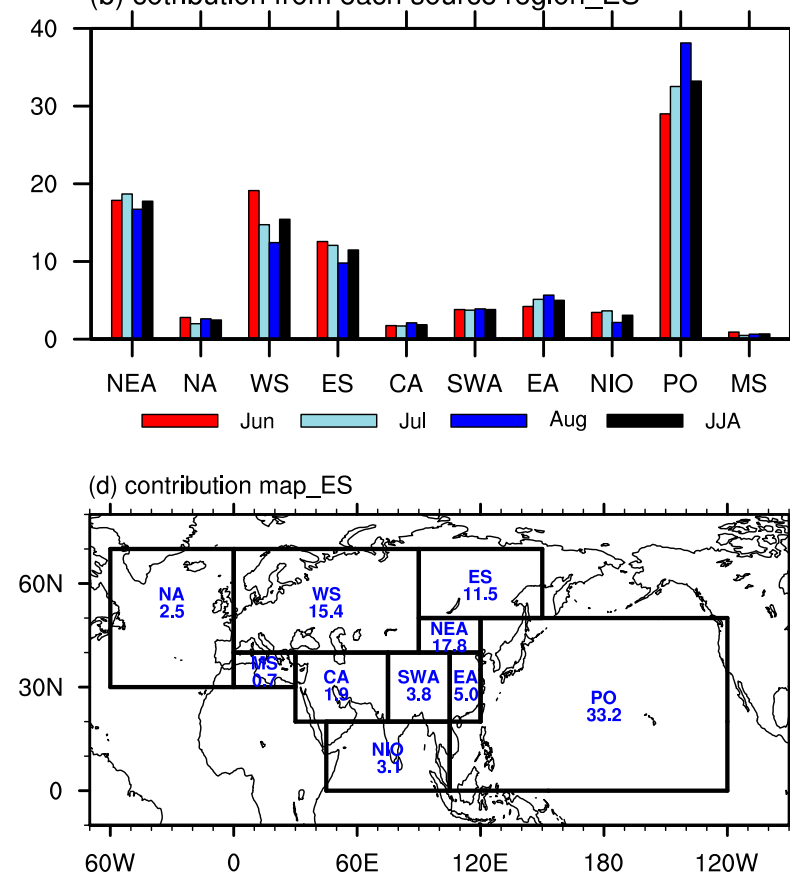

FIG. 5. (a) The contributions from each moisture source to the precipitation over northeast Asia for June (red bar), July (light blue bar), August (dark blue bar), and summer mean (black bar) (\%). (b) As in (a), but for east Siberia. The geographical boundaries of the 10 selected moisture sources, with the contributions (\%) attached below the name of the corresponding moisture sources over (c) northeast Asia and (d) east Siberia.

dominant moisture sources for the summer precipitation over northeast Asia, with contributions of approximately $22.3 \%, 21.6 \%$, and $17.9 \%$, respectively (Figs. $5 a, c$ ). This result is consistent with previous findings regarding the large impacts of the land processes (Fujinami et al. 2016; Fukutomi et al. 2003) and the East Asian summer monsoon (Drumond et al. 2011; Sun et al. 2007; Zhou and Yu 2005) on the northeast Asian moisture supply. In addition, the moisture from southwestern Asia, west Siberia, and the northern Indian Ocean accounts for approximately $11.8 \%, 8.5 \%$, and $7.1 \%$ of the total summer precipitation.

Then, do notable discrepancies exist among the three summer months (i.e., June, July, and August)? To answer this question, the contributions of the 10 moisture sources for June, July, and August were also calculated (Fig. 5a). In June, the largest amount of moisture comes from local evaporation, with a contribution of approximately $21.0 \%$, followed by $19.5 \%$ from the Pacific Ocean. The moisture supplied by East Asia, southwestern Asia, and west Siberia contributes $15.8 \%$, $12.3 \%$, and $11.9 \%$, respectively. In July, the results are similar to those in June for the local evaporation $(21.7 \%)$ and Pacific Ocean $(20.6 \%)$ contributions. The contribution from East Asia shows a significant increase from $15.8 \%$ to $18.5 \%$, while the contribution from west
Siberia decreased from $11.9 \%$ to $7.1 \%$. This finding is associated with the southerly intensification over East Asia and the weakening of the midlatitude westerly (not shown). In August, the contribution from the Pacific Ocean reaches its maximum of $26.7 \%$. The moisture from local evaporation and East Asia contributes 22.1\% and $19.4 \%$, respectively. The above results generally indicate that the summer precipitation over northeast Asia mainly relies on the combined impacts of the moisture supplied from local evaporation, the Pacific Ocean, and East Asia.

In terms of east Siberia, the moisture from the Pacific Ocean, northeast Asia, west Siberia, and local evaporation play key roles in the total summer precipitation, with contributions of approximately $33.2 \%, 17.8 \%$, $15.4 \%$, and $11.5 \%$, respectively (Figs. $5 \mathrm{~b}, \mathrm{~d}$ ). Note that most previous studies regard local evaporation as the main moisture source for east Siberian precipitation (Fujinami et al. 2016; Serreze and Etringer 2003). This may be because these studies are mainly based on the vertically integrated water vapor flux. It is reasonable that the Pacific Ocean plays an important role in the moisture supply because the moisture provided by the local evaporation is limited (Numaguti 1999). For each month during summer, the contribution from northeast Asia is relatively stable with no obvious variations 


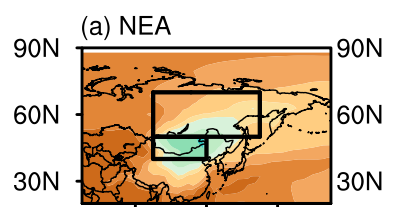

80E 120E 160E

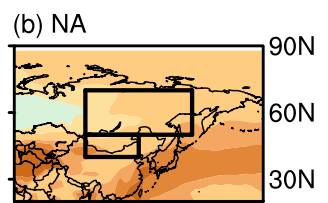

80E 120E 160E

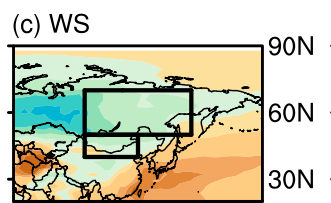

80 E 120E 160E

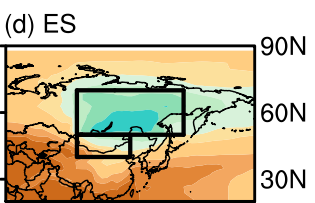

80 E 120E 160E

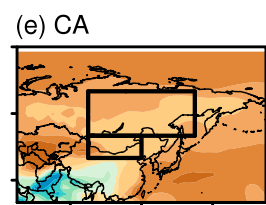

80E 120E 160E

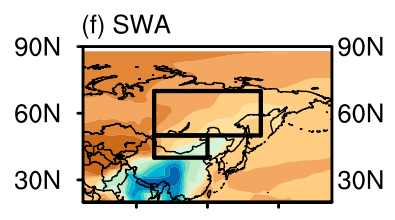

80E 120E 160E

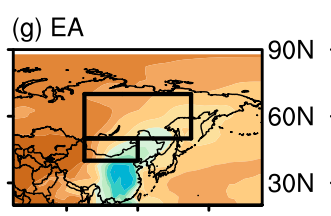

80E 120E 160E

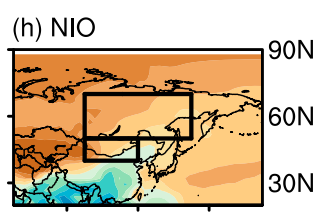

$80 \mathrm{E} 120 \mathrm{E} 160 \mathrm{E}$

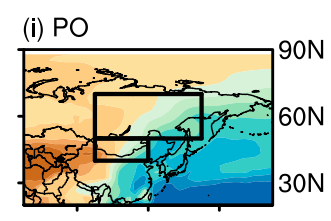

80E 120E 160E

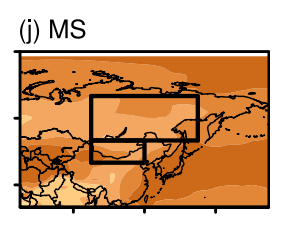

80E 120E 160E

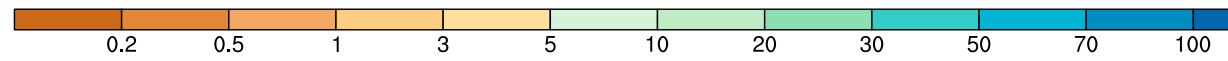

FIG. 6. Spatial distribution of the climatological summer precipitation ( $\left.\mathrm{mm} \mathrm{month}{ }^{-1}\right)$ that originates from (a) northeast Asia, (b) North Atlantic Ocean, (c) west Siberia, (d) east Siberia, (e) central Asia, (f) southwestern Asia, (g) East Asia, (h) northern Indian Ocean, (i) Pacific Ocean, and (j) Mediterranean Sea.

(Fig. 5b). The moisture that originates from west Siberia shows a gradual decrease from June $(19.1 \%)$ to August $(12.4 \%)$, which may be due to weakening of the westerly jet (not shown). Simultaneously, the local evaporation contribution is also reduced from $12.6 \%$ in June to $9.8 \%$ in August, under the potential impact from the regional temperature decrease. In contrast, the contribution from the Pacific Ocean increased from $29 \%$ in June to $38.1 \%$ in August. In conclusion, moisture from the Pacific Ocean has a leading role in the summer precipitation over east Siberia, with a relatively small contribution from northeast Asia, west Siberia, and local evaporation.

Figure 6 further shows the spatial distribution of the summer precipitation that originates from each source region. The moisture from the Pacific Ocean mainly contributes to the summer precipitation over the southeastern part of northeast Asia and east Siberia, ranging from 5 to $40 \mathrm{~mm}$ month $^{-1}$ (Fig. 6i). The moisture from west Siberia gradually decreases from 20-30 to $5-10 \mathrm{~mm} \mathrm{month}^{-1}$ in the west-east direction over east Siberia, with a north-south gradient from 10-20 to 5-10 mm month ${ }^{-1}$ over northeast Asia (Fig. 6c). The local evaporation supplies $5-30 \mathrm{~mm}$ month $^{-1}$ precipitation over the two target regions (Figs. 6a,d), with the maximum located over the center position. The moisture that evaporated over northeast Asia presents a northward extension to east Siberia, with a contribution of approximately 5-20 mm month ${ }^{-1}$ (Fig. 6a). In contrast, the surface evaporation contribution over east Siberia seems to be mainly limited in its own area, with a stretch eastward to the Russian Far East (Fig. 6d). The moisture from East Asia is mainly distributed in the eastern part of northeast Asia, with a south-to-north gradient from
30 to $5 \mathrm{~mm}$ month $^{-1}$ (Fig. $6 \mathrm{~g}$ ). The above evidence indicates that the contribution from moisture sources largely varies for different parts of northeast Asia and east Siberia.

\section{c. Interdecadal variation in the summer precipitation mode around the late 1990s}

Driven by the observed SST from the Hadley Centre, the model has difficulties in reproducing the observed precipitation variation over northeast Asia or east Siberia. Previous studies pointed out that the dipole pattern between the two target regions experiences an interdecadal variation around the late 1990s (Iwao and Takahashi 2006), accompanied with the interdecadal decrease in summer precipitation over Northeast China during the late 1990s. The SST anomalies are regarded as one important influencing factor, including the Pacific decadal oscillation (PDO) (Xu et al. 2015; Zhu et al. 2011), and SST warming over the North Atlantic Ocean (Piao et al. 2017). Considering this, we mainly discussed the response of the dipole precipitation pattern between the two regions and the related moisture supply to the decadal variability of SST.

First, we evaluate the model performance in capturing the dipole pattern between the two target regions. Figure 7 shows the first EOF mode of summer precipitation over eastern Eurasia along with the corresponding principal component (PC) time series obtained from the GPCP data and CAM3 output. In the GPCP, the first EOF mode (Fig. 7a) shows an oscillation in the precipitation anomalies between northeast Asia and east Siberia, which is consistent with the results of previous studies (Iwao and Takahashi 2006). The corresponding PC time series (Fig. 7b) experiences a significant 
(a) GPCP_EOF1

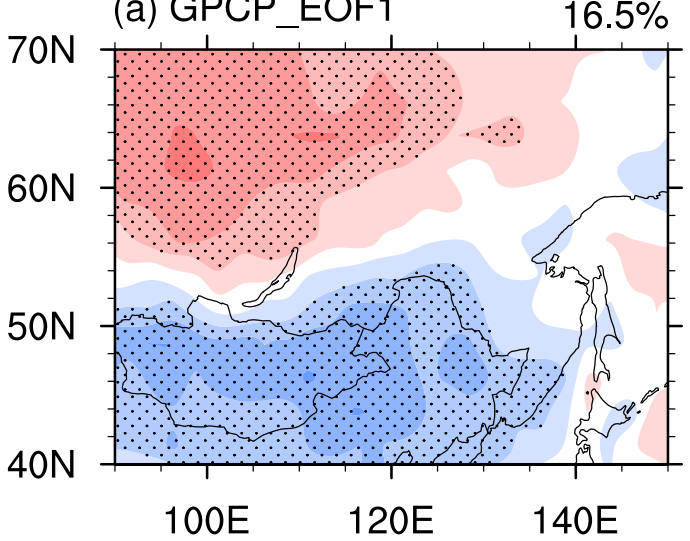

(c) CAM3_EOF1

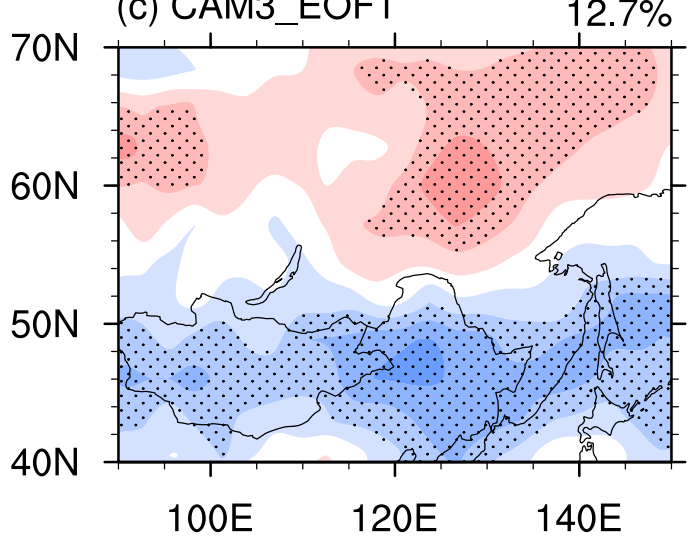

(b) GPCP_EOF1_ts

2.

0.

-1 .

-2 .

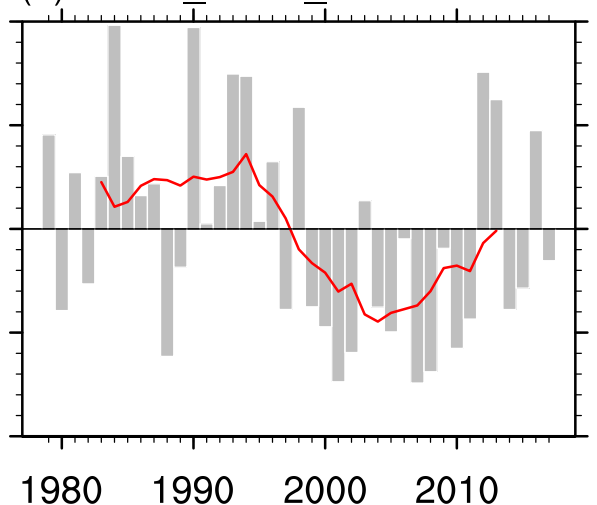

(d) CAM3_EOF1_ts
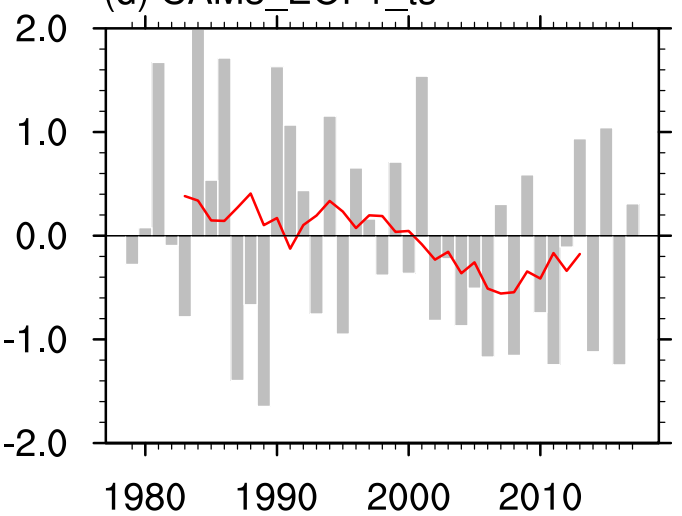

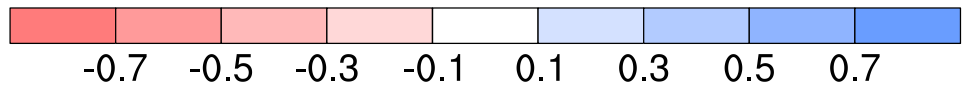

FIG. 7. Spatial pattern of the correlation coefficients between the summer precipitation and the PC time series corresponding to the first EOF of summer precipitation over east Eurasia $\left(90^{\circ}-150^{\circ} \mathrm{E}, 40^{\circ}-70^{\circ} \mathrm{N}\right)$ obtained from (a) GPCP and (c) CAM3 during 1979-2017. The corresponding PC time series of the first EOF mode of summer precipitation and its interdecadal component calculated by a 9 year smoothing (red line) obtained from (b) GPCP and (d) CAM3. Dotted areas in (a) and (c) denote the correlation coefficients that are significant above the $95 \%$ confidence level based on the two-tailed Student's $t$ test.

interdecadal shift with excessive (deficient) summer precipitation over northeast Asia (east Siberia) before (after) the late 1990s, as shown in the study by Iwao and Takahashi (2006). The dipole pattern can be well reproduced by the CAM3 model output, with positive anomalies centered over Mongolia, Northeast China, and Sakhalin, together with anomalies that have the opposite signs over east Siberia centered on the eastern part of Russia (Fig. 7c). The anomaly centers related to the first EOF mode shift eastward in the model simulations compared to the GPCP results (Figs. 7a,c). However, the model can reproduce the interdecadal variation in the dipole pattern around the late 1990s (Fig. 7d), although the amplitude is slightly weaker than that in the GPCP (Fig. 7b). In general, the CAM3 output could reproduce the spatial structure of the dipole precipitation anomaly pattern over east Eurasia as well as the interdecadal change in precipitation around the late 1990s. In the following, two periods before and after the late 1990s (i.e., 1979-96 and 1997-2017) are further selected to investigate the interdecadal change.

The summer precipitation differences between the periods of 1997-2017 and 1979-96 show positive anomalies over east Siberia and negative signals over northeast Asia for the GPCP data (Fig. 8a). Similar signals can be obtained in the CAM3 results, with discrepancies in the locations of the significant centers. In particular, negative centers are observed over the eastern part of northeast Asia, and positive centers appear in the northern and eastern parts of east Siberia for the 
(a) GPCP_precip_dif

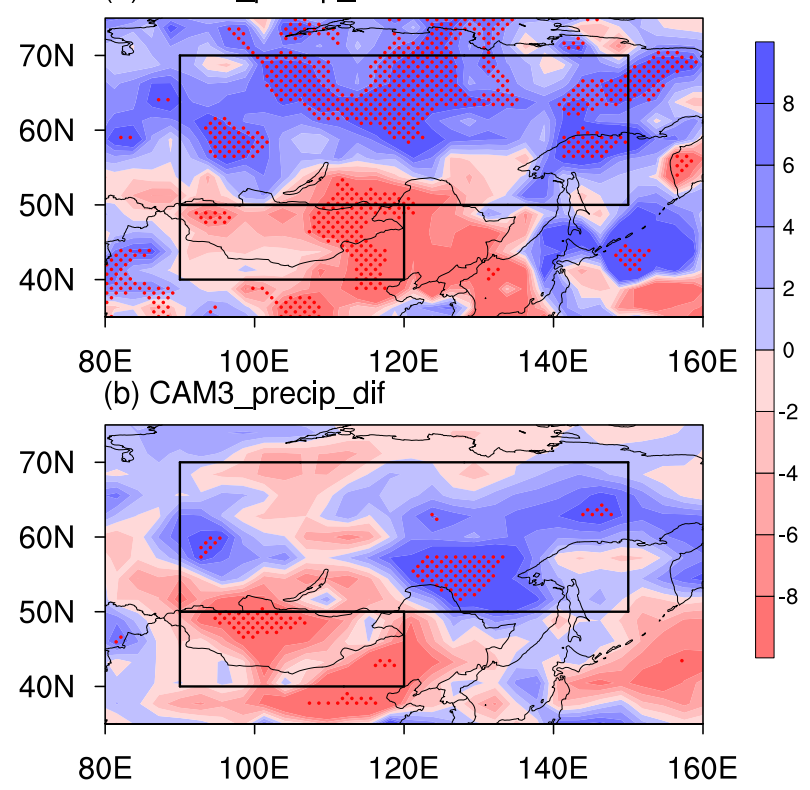

FIG. 8. Differences in the summer precipitation between 19972017 and 1979-96 based on (a) GPCP and (b) CAM3 (mm month ${ }^{-1}$ ). Stippled regions represent the differences that are significantly different from zero at the $95 \%$ confidence level based on the two-tailed Student's $t$ test.

GPCP data. For CAM3, negative (positive) centers are located over the northern and southeastern parts of northeast Asia (eastern part of east Siberia) (Fig. 8b). Noting that, opposite signals are identified over the northwestern Pacific and small patches over the western part of east Siberia between GPCP and CAM3 results, with positive anomalies for the former but negative for the latter. Though there are relatively weak positive signals over east Siberia for the CAM3 output, the difference of the summer precipitation between post- and pre-1997 is significant at the $90 \%$ confidence level based on Student's $t$ test, with the amount of $75.4(73.0) \mathrm{mm} \mathrm{month}^{-1}$ for the former (latter) period. These biases may result from the coarse resolution and internal variability of the model, as mentioned in previous studies (Orth and Seneviratne 2017; Salih et al. 2016; Sato and Nakamura 2019). Can the interdecadal change in the dipole precipitation anomaly mode be manifested by the contribution of any selected moisture source? To answer this question, we calculated differences in summer precipitation between the periods of 1997-2017 and 1979-96 supplied by the 10 moisture sources (Fig. 9). Among all the moisture sources, the moisture that originates from east Siberia (Fig. 9d) and the Pacific Ocean (Fig. 9i) exhibits the most similar pattern to that of the total summer precipitation (Fig. 8b), which is characterized by positive anomalies over the eastern part of east Siberia and anomalies with opposing signals over northeast Asia. Apart from this, the summer precipitation supplied by northeast Asia mainly has negative anomalies over its northern part, accompanied by positive anomalies over the eastern part of east Siberia, which are statistically insignificant (Fig. 9a). The moisture from the northern Atlantic Ocean and west Siberia shows positive signals mainly over east Siberia (Figs. 9b,c). The moisture provided by southwestern Asia, East Asia, and the northern Indian Ocean present similar spatial patterns, but the signals are relatively weak (Figs. 9f-h). In addition, the moisture from central Asia and the Mediterranean Sea has weak contributions (Figs. 9e,j).

The first EOF mode and corresponding PC time series of the summer precipitation supplied by the 10 moisture

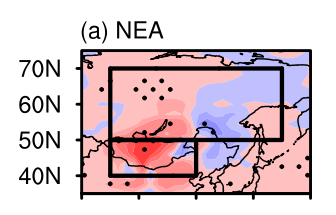

$80 \mathrm{E} 100 \mathrm{E} 120 \mathrm{E} 140 \mathrm{E} 160 \mathrm{E}$

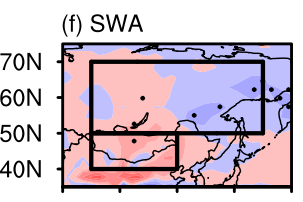

$80 E$ 100E 120E 140E 160E (b) NA

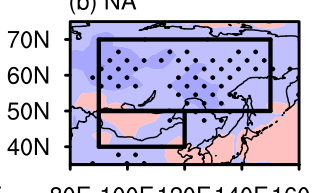

80E 100E 120E 140E 160E

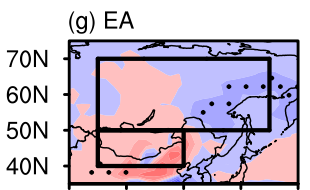

80 E 100E 120E 140E 160E (c) WS

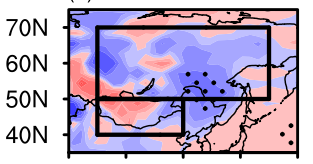

80 E 100E 120E 140E 160E

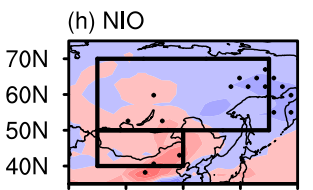

80 E 100E 120E 140E 160E (d) ES

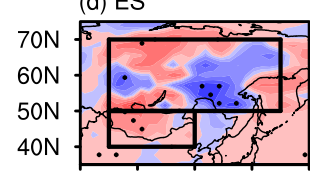

80 E 100E 120E 140E 160E

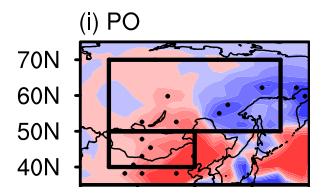

80 E 100E 120E 140E 160E

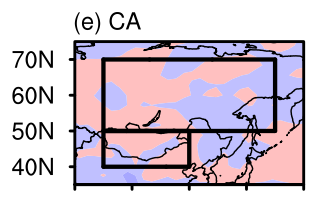

80 E 100E 120E 140E 160E

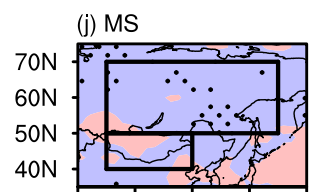

80 E 100E 120E 140E 160E

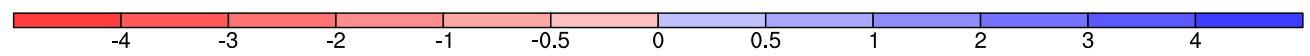

FIG. 9. Differences in the summer precipitation between 1997-2017 and 1979-96 that originate from (a) northeast Asia, (b) North Atlantic Ocean, (c) west Siberia, (d) east Siberia, (e) central Asia, (f) southwestern Asia, (g) East Asia, (h) northern Indian Ocean, (i) Pacific Ocean, and (j) Mediterranean Sea $\left(\mathrm{mm} \mathrm{month}^{-1}\right)$. Stippled regions in (a)-(j) represent the differences that are significantly different from zero at the $95 \%$ confidence level based on the two-tailed Student's $t$ test. 

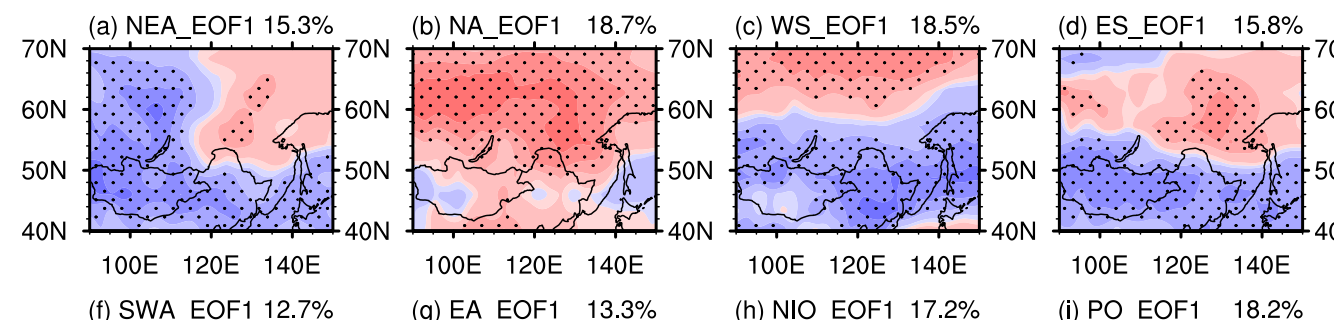

(e) CA_EOF1 $23.2 \%$
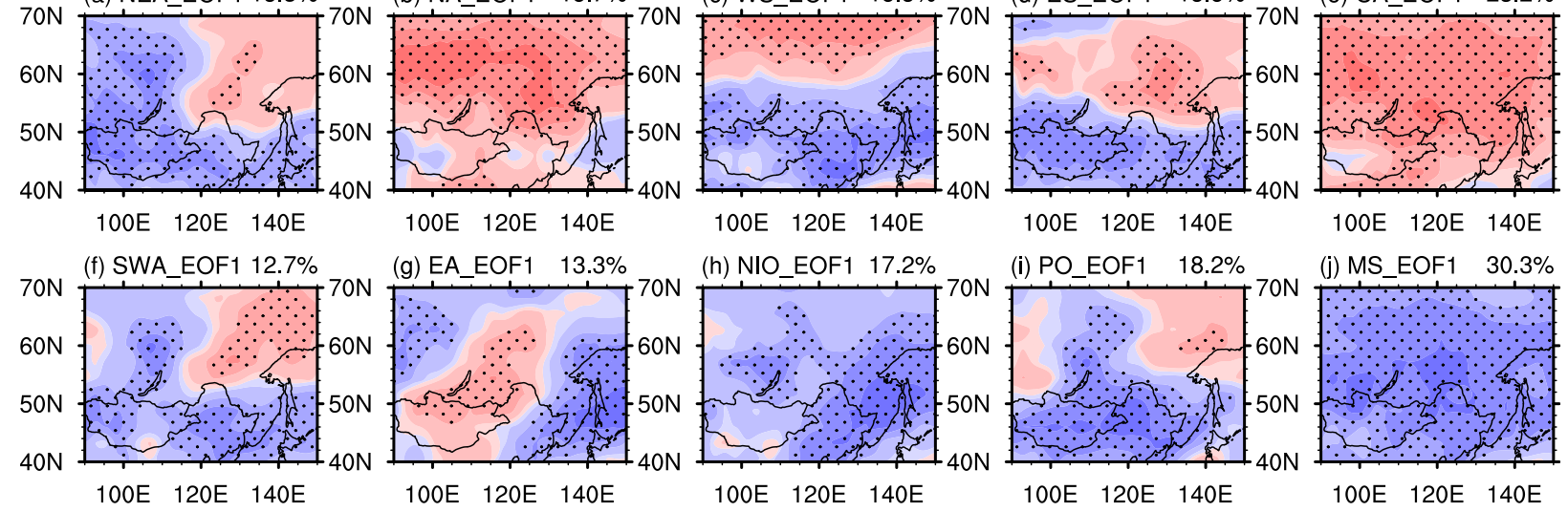

$100 \mathrm{E} \quad 120 \mathrm{E} \quad 140 \mathrm{E}$

$100 \mathrm{E} \quad 120 \mathrm{E} \quad 140 \mathrm{E}$

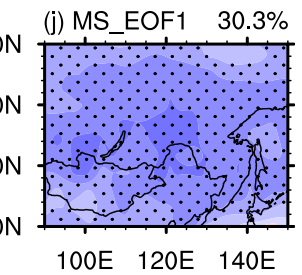

$$
-0.7
$$

$$
-0.3
$$
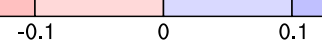

$$
0.3
$$

0.5

$$
0.7
$$

FIG. 10. The spatial pattern of the correlation coefficients between the summer precipitation and the PC time series of the first EOF of the summer precipitation over east Eurasia that originates from (a) northeast Asia, (b) North Atlantic Ocean, (c) west Siberia, (d) east Siberia, (e) central Asia, (f) southwestern Asia, (g) East Asia, (h) northern Indian Ocean, (i) Pacific Ocean, and (j) Mediterranean Sea. Dotted areas in (a)-(j) denote the correlation coefficients that are significant above the $95 \%$ confidence level based on the two-tailed Student's $t$ test.

sources are further presented in Figs. 10 and 11, respectively. Compared to the dipole pattern shown for the total summer precipitation (Fig. 7c), similar patterns can be recognized in the first EOF mode for northeast Asia (Fig. 10a), west Siberia (Fig. 10c), east Siberia (Fig. 10d), southwestern Asia (Fig. 10f), and the Pacific Ocean (Fig. 10i), with positive anomalies over northeast Asia and negative signals over east Siberia. In addition, negative signals are limited within east Siberia in the North Atlantic Ocean (Fig. 10b) and central Asia (Fig. 10e); the spatial pattern shows significant signals over northern China for the northern Indian Ocean (Fig. 10h) and a larger area including northeast Asia and east Siberia for the Mediterranean Sea (Fig. 10j). On the other hand, the interdecadal variation in the dipole pattern around the late 1990s can be well simulated in the cases for northeast Asia (Fig. 11a), the North Atlantic Ocean (Fig. 11b), east Siberia (Fig. 11d), southwestern Asia (Fig. 11f), and the Pacific Ocean (Fig. 11i). Based on the calculations, significant relationships exist between the PC time series of the first EOF mode for the total summer precipitation and the summer precipitation that originates from the North Atlantic Ocean, east Siberia, and the Pacific Ocean on the interdecadal time scale, with correlation coefficients of $0.83,0.89$, and 0.9 , respectively. Note that the first (a) NEA_EOF1

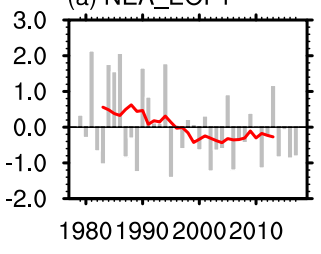

(f) SWA_EOF1

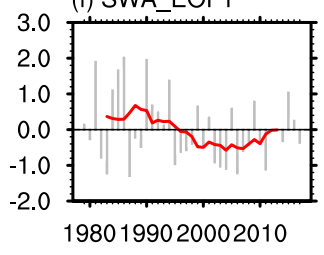

(b) NA EOF1

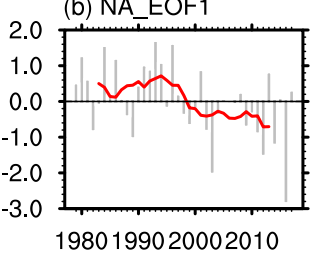

(g) EA_EOF1

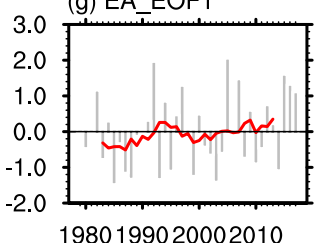

(c) WS EOF1

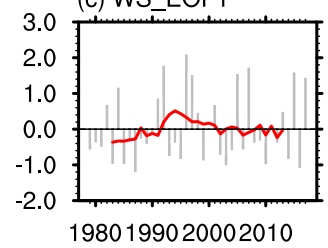

(h) NIO_EOF1

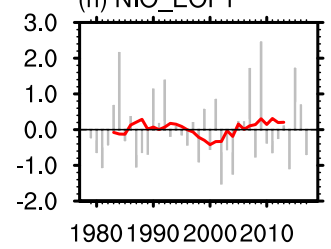

(d) ES EOF1

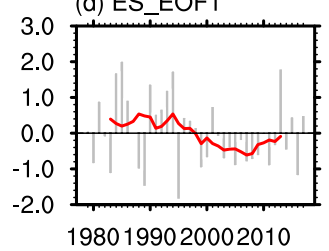

(i) PO_EOF1

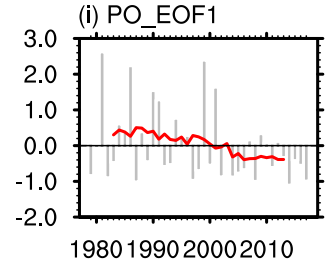

(e) CA EOF1

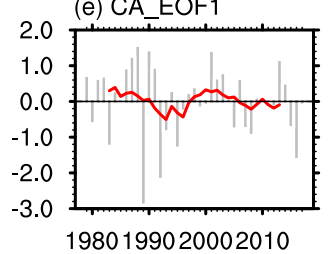

(j) MS_EOF1

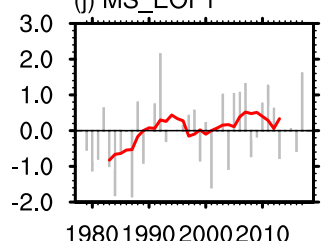

FIG. 11. The PC time series (gray bar) of the first EOF mode of summer precipitation over east Eurasia that is supplied by (a) northeast Asia, (b) North Atlantic Ocean, (c) west Siberia, (d) east Siberia, (e) central Asia, (f) southwestern Asia, (g) East Asia, (h) northern Indian Ocean, (i) Pacific Ocean, and (j) Mediterranean Sea. The red lines in the figures represent the corresponding interdecadal components of the PC time series. 
EOF mode for the North Atlantic Ocean features significant signals that are limited within east Siberia (Fig. 10b), implying that the moisture from this source region mainly contributes to the dipole mode variation through its impact on the summer precipitation over east Siberia. In the combination of the spatial distribution and corresponding PC time series of the first EOF mode, the moisture from east Siberia and the Pacific Ocean seems to mainly contribute to the interdecadal variation in the dipole mode in the summer precipitation between the two target regions, with the moisture from the North Atlantic exerting impacts mainly on the summer precipitation over east Siberia.

Accompanied with the interdecadal variation of the summer precipitation pattern and water supply over the two target regions in the late 1990s, significant differences are identified in the water vapor transport circulations between the periods of 1997-2017 and 1979-96 (Fig. 12). Anticyclonic and cyclonic circulations appear over northeast Asia and east Siberia for both the reanalysis result and model output (Figs. 12a,b), with the cyclonic (anticyclonic) center shifted eastward (weaken) for the latter one (Fig. 12b). Significant divergence (convergence) covers northeast Asia (east Siberia) in the reanalysis result, which corresponds well to the negative (positive) rainfall anomalies. The model output shows similar results except for the weak convergence over the western part of northeast Asia and the middle part of east Siberia (Fig. 12b), which is generally consistent with the rainfall anomalies shown in the model output (Fig. 8b). The terms $\mathbf{Q}_{\text {wind }}^{\prime}$ and $\mathbf{Q}_{\text {moisture }}^{\prime}$ are representative of the role of the disturbance in the wind and moisture field on the water vapor transport anomaly, respectively. The sum of the two terms generally captures the main features of the changes in the water vapor transport (figure not shown). The differences of $\mathbf{Q}_{\text {wind }}^{\prime}$ between the periods of 1997-2017 and 1979-96 are quite similar to those in the total water vapor transport in the perspective of both reanalysis results and model output (Figs. 12c,d), in sharp contrast to the weak and even opposite signals for $\mathbf{Q}_{\text {moisture }}^{\prime}$ (Figs. 12e,f). Hence, the disturbance wind field plays a dominant role in the water vapor transport changes after the late 1990s.

Considering the geopotential height field, differences are significant and present positive values over western Europe, northeast Asia, and the northwestern Pacific between the periods of 1997-2017 and 1979-96 for the reanalysis data (Fig. 13a). The positive centers over the three regions can still be recognized in the model simulations, although the latter two shifts westward compared to the reanalysis results (Fig. 13b). Some studies attributed these circulation anomalies to the shift of the PDO from a warm phase to a cold phase in the late 1990s (e.g., Dai 2013; Deser et al. 2004; Peterson and Schwing 2003). For instance, Zhu et al. (2011) obtained the similar circulation pattern in the numerical experiments when the all-Pacific SST differences between post- and pre-1999 are prescribed. As the dominant oceanic signal over the Atlantic Ocean, the Atlantic multidecadal oscillation (AMO) (e.g., Enfield et al. 2001; Kerr 2000; Kushnir 1994; Schlesinger and Ramankutty 1994) is also considered to contribute to this interdecadal climate change (Li et al. 2017; Qian et al. 2014; Sutton and Dong 2012). And the AMO is pointed out as an influencing factor for the phase shift of the PDO around the late 1990s (McGregor et al. 2014; Li et al. 2016). Following this, the joint influence of the AMO and PDO is further investigated and considered to play an important role on the circulation anomalies in the late 1990s as mentioned above (Zhang et al. 2018). Since the observed SST data are the only forcing for the model simulation, it is reasonable to speculate that the geopotential height anomalies shown in Fig. 13b are under the combined effects of the PDO and AMO.

From the perspective of rain-producing atmospheric systems, the anomalous anticyclone and cyclone located over northeast Asia and east Siberia are favorable for precipitation variations after the late 1990s. From the other perspective concerning moisture transport, the anomalous anticyclone over the northwestern Pacific is favorable for moisture transport from the Pacific Ocean to east Siberia, accounting for the close relationship of the moisture that originates from the Pacific Ocean to the interdecadal variation in the summer precipitation mode; the anticyclones over western Europe and northeast Asia may impact the contribution of the moisture supplied by the North Atlantic Ocean via the strengthened westerly jet (Numaguti 1999) observed over the Eurasian continent (Fig. 13b). For the moisture from east Siberia, the interpretation of its contribution is complicated due to the involvement of the feedback between the surface evaporation and the summer precipitation within this area.

\section{Conclusions and discussion}

In this study, we quantified the contributions from different moisture sources for summer precipitation over northeast Asia and east Siberia and further discussed the relationships between summer precipitation and moisture sources on the interdecadal time scale. A general circulation model CAM3 with a water-tagging module forced by the observed SST is employed to trace the water vapor from the evaporation over the source region to its falling as precipitation over the target region. The model generally captures the spatial distribution and 
(a)

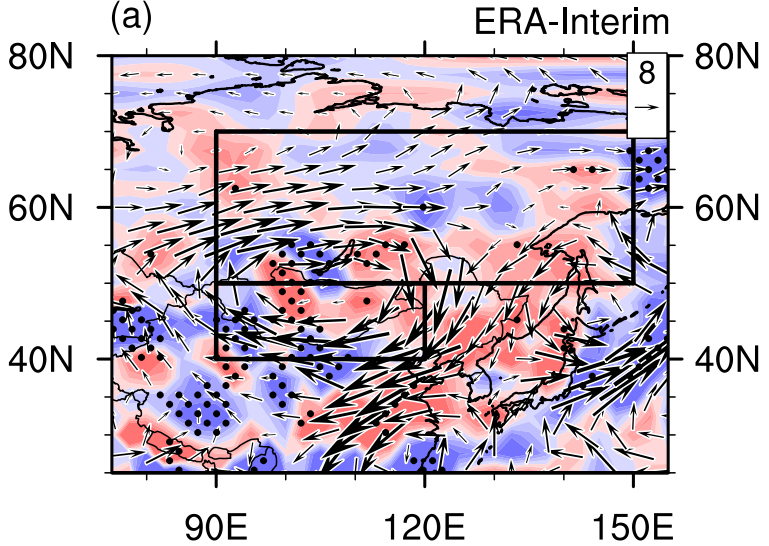

(c)

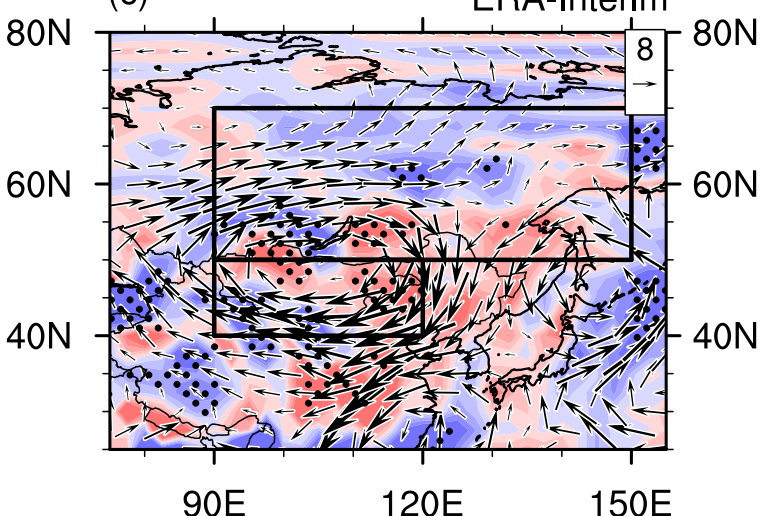

(e)

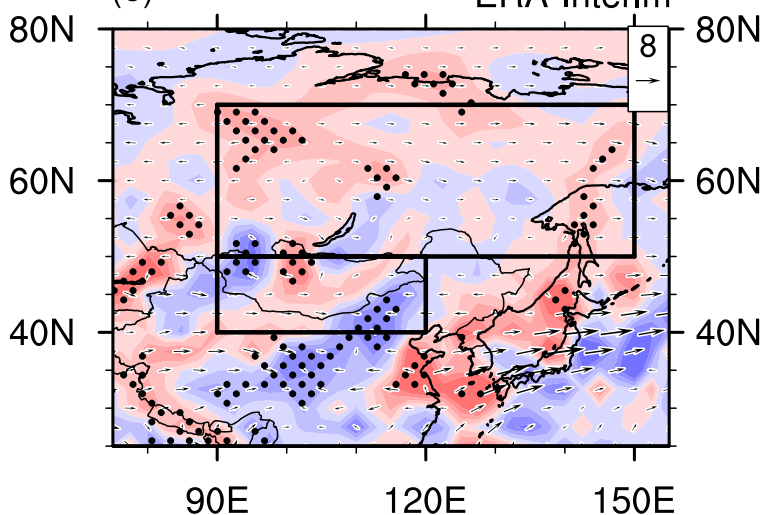

(b)

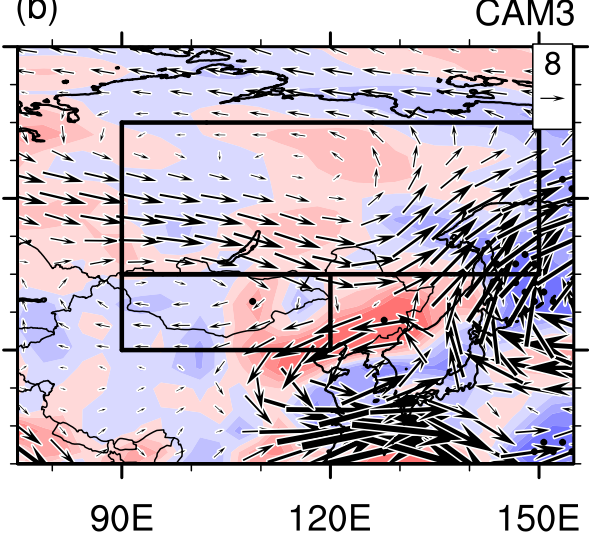

(d)

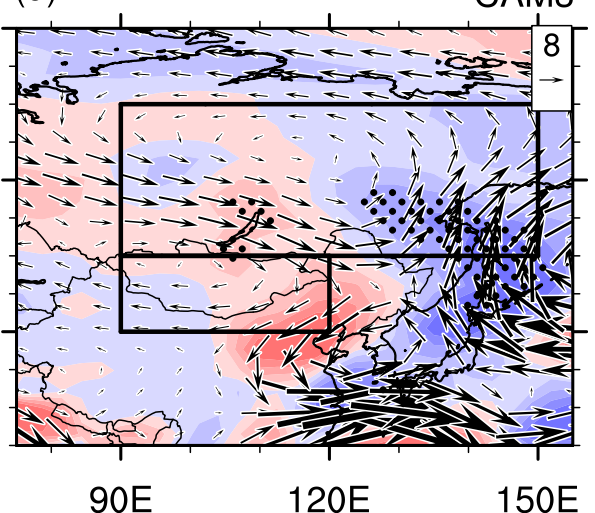

(f)

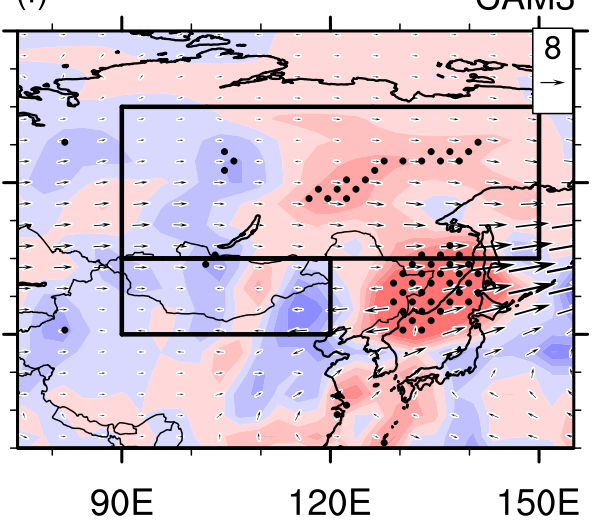

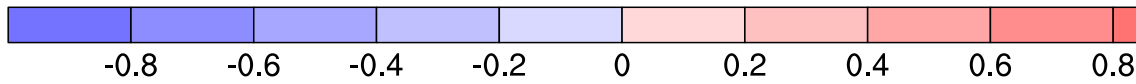

FIG. 12. Differences in the vertically integrated water vapor flux (vectors; $\mathrm{kg} \mathrm{m}^{-1} \mathrm{~s}^{-1}$ ) and its divergence (shadings; $10^{-5} \mathrm{~kg} \mathrm{~m}^{-2} \mathrm{~s}^{-1}$ ) in summer between 1997-2017 and 1979-96 based on (a) ERA-Interim and (b) CAM3. (c),(d) As in (a) and (b), but for the mean moisture field transported by the disturbance wind $\mathbf{Q}_{\text {wind }}^{\prime}$. (e),(f) As in (a) and (b), but for the disturbance moisture field transported by the mean wind $\mathbf{Q}_{\text {moisture }}^{\prime}$. Stippled regions represent differences in the water vapor flux divergence that are significantly different from zero at the $95 \%$ confidence level based on the two-tailed Student's $t$ test.

annual cycle of precipitation, following the main controlling atmospheric systems over the regions of interest.

Based on the model results, the Pacific Ocean, local evaporation, and East Asia are dominant moisture sources for northeast Asia, accounting for $22.3 \%$, $21.6 \%$, and $17.9 \%$ of the total moisture supply, respectively. This finding supports the importance of surface water recycling and the East Asian summer monsoon on 
(a) 850 hPa UV_dif
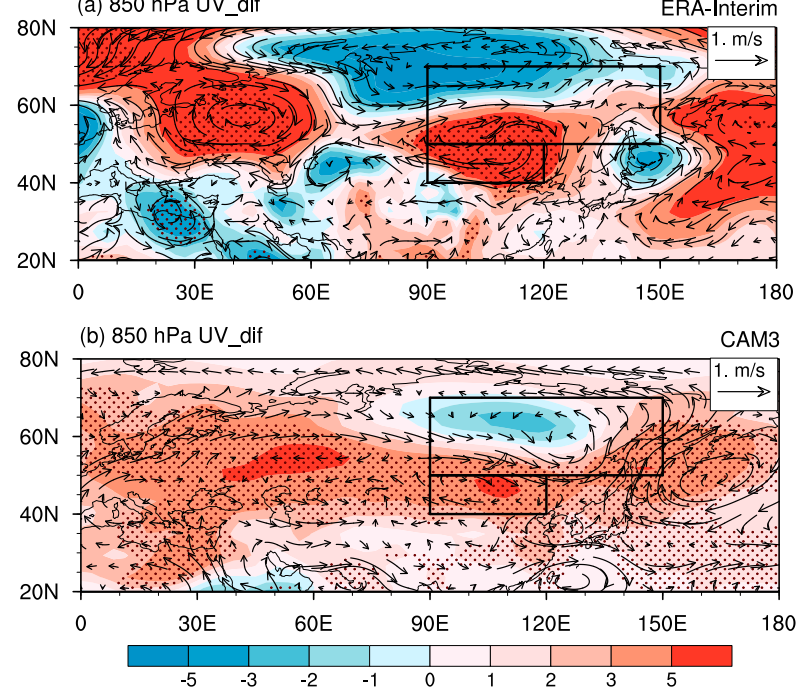

FIG. 13. Differences in the $850-\mathrm{hPa}$ horizontal wind (vectors; $\mathrm{m} \mathrm{s}^{-1}$ ) and geopotential height (shadings; $\mathrm{m}$ ) in summer between 1997-2017 and 1979-96 based on (a) ERA-Interim and (b) CAM3. Stippled regions represent differences in the geopotential height that are significantly different from zero at the $95 \%$ confidence level based on the two-tailed Student's $t$ test.

the moisture input within this region. The moisture from southwestern Asia, west Siberia, and the northern Indian Ocean exert relatively small impacts, with contributions of approximately $11.8 \%, 8.5 \%$, and $7.1 \%$, respectively. For east Siberia, the moisture from the Pacific Ocean, northeast Asia, west Siberia, and the local evaporation play the dominant roles, contributing $33.2 \%, 17.8 \%, 15.4 \%$, and $11.5 \%$ to the total summer precipitation, respectively. The significant role of these regions provides evidence of the major influence of the surface land process, the adjacent continent, and oceanic sources on the moisture supply within east Siberia. No obvious seasonality exists in the contribution from each moisture source over the two target regions because there is no apparent difference in the relative importance of the main moisture sources among June, July, and August.

An interdecadal shift appears in the dipole pattern of summer precipitation between northeast Asia and east Siberia around the late 1990s in the model output, as shown in the observations. Differences in the summer precipitation between the two periods after and before 1997 display above-normal anomalies concentrated over east Siberia and below-normal anomalies over northeast Asia. This interdecadal shift is manifested in the moisture supplied by east Siberia and the Pacific Ocean, with similar spatial patterns and significant anomalies. In addition, the first EOF mode of the moisture supplied by the two regions also presents a similar dipole pattern, with the corresponding PC time series experiencing an interdecadal change around the late 1990s. A close relationship exists between the PC time series of the first EOF for the total summer precipitation and the moisture from east Siberia (Pacific Ocean) on the decadal time scale, with a correlation as high as $0.89(0.9)$. The model results also showed that the interdecadal variation in the total summer precipitation over east Siberia can be partly attributed to moisture changes from the North Atlantic Ocean. Our preliminary analysis suggested that their close relationships may result from the anomalous anticyclones over the northwestern Pacific, northeast Asia, and the western Pacific influenced by a combination of PDO and AMO. It is worth noting that the model simulation is forced by the observed SST, which suggests that the decadal variation of SST should not sufficiently account for the atmospheric circulation anomalies after the late 1990s. In addition to SST, the coupled land-atmosphere system plays a nonnegligible role in the climate change over the midlatitude Eurasian continent based on general circulation model experiments (Orth and Seneviratne 2017; Sato and Nakamura 2019). Hence, the internal dynamical processes of the model involving the landatmospheric interaction might be another influencing factor.

The identification of dominant moisture sources is of great importance for our better understanding of the regional hydrological cycle and can exert profound impacts on future climate predictions. Considering the sensitivity of the hydrological cycle in the research area to climate change, there are still some issues to be solved: what is the response of the hydrological situation to future climate change, especially under the impact of global warming? And to what extent can it affect precipitation changes in the future? These issues are directly related to the sustainable development of the two regions and can provide scientific support for our preparations for future climate change.

Acknowledgments. We thank the three anonymous reviewers for their constructive suggestions and comments, which helped to improve the paper. This study was jointly supported by the National Key Research and Development Program of China (Grant 2016YFA0600604), the Swedish Foundation for International Cooperation in Research and Higher Education (STINT: CH2016-6711), and the Jiangsu Collaborative Innovation Center for Climate Change. The CAM3 model simulations were performed on a supercomputer provided by the Swedish National Infrastructure for Computing (SNIC) at NSC and Cray XC30 HPC systems at ECMWF. 


\section{REFERENCES}

Adler, R. F., and Coauthors, 2003: The version-2 Global Precipitation Climatology Project (GPCP) monthly precipitation analysis (1979-present). J. Hydrometeor., 4, 1147-1167, https://doi.org/ 10.1175/1525-7541(2003)004<1147:TVGPCP $>2.0 . C O ; 2$.

Bosilovich, M. G., and S. D. Schubert, 2002: Water vapor tracers as diagnostics of the regional hydrologic cycle. J. Hydrometeor., 3, 149-165, https://doi.org/10.1175/1525-7541(2002)003<0149: WVTADO $>2.0 . \mathrm{CO} ; 2$.

_- and J. D. Chern, 2006: Simulation of water sources and precipitation recycling for the MacKenzie, Mississippi, and Amazon River basins. J. Hydrometeor., 7, 312-329, https:// doi.org/10.1175/JHM501.1.

Bowman, K. P., J. C. Lin, A. Stohl, R. Draxler, P. Konopka, A. Andrews, and D. Brunner, 2013: Input data requirements for Lagrangian trajectory models. Bull. Amer. Meteor. Soc., 94, 1051-1058, https://doi.org/10.1175/BAMS-D-12-00076.1.

Chen, W., L. Wang, Y. Xue, and S. Sun, 2009: Variabilities of the spring river runoff system in East China and their relations to precipitation and sea surface temperature. Int. J. Climatol., 29, 1381-1394, https://doi.org/10.1002/joc.1785.

— J. Feng, and R. Wu, 2013: Roles of ENSO and PDO in the link of the East Asian winter monsoon to the following summer monsoon. J. Climate, 26, 622-635, https://doi.org/10.1175/ JCLI-D-12-00021.1.

Chuai, X., X. Huang, W. Wang, and G. Bao, 2013: NDVI, temperature and precipitation changes and their relationships with different vegetation types during 1998-2007 in Inner Mongolia, China. Int. J. Climatol., 33, 1696-1706, https:// doi.org/10.1002/joc.3543.

Collins, W. D., and Coauthors, 2006: The formulation and atmospheric simulation of the Community Atmosphere Model version 3 (CAM3). J. Climate, 19, 2144-2161, https://doi.org/ 10.1175/JCLI3760.1.

Dai, A., 2013: The influence of the inter-decadal Pacific oscillation on US precipitation during 1923-2010. Climate Dyn., 41, 633646, https://doi.org/10.1007/s00382-012-1446-5.

Dee, D. P., and Coauthors, 2011: The ERA-Interim reanalysis: Configuration and performance of the data assimilation system. Quart. J. Roy. Meteor. Soc., 137, 553-597, https://doi.org/ 10.1002/qj.828.

Delaygue, G., V. Masson, J. Jouzel, R. D. Koster, and R. J. Healy, 2000: The origin of Antarctic precipitation: A modelling approach. Tellus, 52B, 19-36, https://doi.org/ 10.1034/j.1600-0889.2000.00951.x.

Deser, C., A. S. Phillips, and J. W. Hurrell, 2004: Pacific interdecadal climate variability: Linkages between the tropics and the North Pacific during boreal winter since 1900. J. Climate, 17, 3109-3124, https://doi.org/10.1175/1520-0442(2004)017<3109:PICVLB> 2.0.CO;2.

Dickinson, R. E., K. W. Oleson, G. Bonan, F. Hoffman, P. Thornton, M. Vertenstein, Z.-L. Yang, and X. Zeng, 2006: The Community Land Model and its climate statistics as a component of the Community Climate System Model. J. Climate, 19, 2302-2324, https://doi.org/10.1175/JCLI3742.1.

Ding, Q., and B. Wang, 2005: Circumglobal teleconnection in the Northern Hemisphere summer. J. Climate, 18, 3483-3505, https://doi.org/10.1175/JCLI3473.1.

Drumond, A., R. Nieto, and L. Gimeno, 2011: Sources of moisture for China and their variations during drier and wetter conditions in 2000-2004: A Lagrangian approach. Climate Res., 50, 215-225, https://doi.org/10.3354/cr01043.
Endo, N., T. Kadota, J. Matsumoto, B. Ailikun, and T. Yasunari, 2006: Climatology and trends in summer precipitation characteristics in Mongolia for the period 1960-98. J. Meteor. Soc. Japan, 84, 543-551, https://doi.org/10.2151/jmsj.84.543.

Enfield, D. B., A. M. Mestas-Nuñez, and P. J. Trimble, 2001: The Atlantic multidecadal oscillation and its relation to rainfall and river flows in the continental U.S. Geophys. Res. Lett., 28, 2077-2080, https://doi.org/10.1029/2000GL012745.

Fujinami, H., T. Yasunari, and T. Watanabe, 2016: Trend and interannual variation in summer precipitation in eastern Siberia in recent decades. Int. J. Climatol., 36, 355-368, https://doi.org/ $10.1002 /$ joc. 4352 .

Fukutomi, Y., H. Igarashi, K. Masuda, and T. Yasunari, 2003: Interannual variability of summer water balance components in three major river basins of northern Eurasia. J. Hydrometeor., 4, 283-296, https://doi.org/10.1175/1525-7541(2003)4<283:IVOSWB> 2.0.CO; 2

Gates, W. L., and Coauthors, 1999: An overview of the results of the Atmospheric Model Intercomparison Project (AMIP I). Bull. Amer. Meteor. Soc., 80, 29-56, https://doi.org/10.1175/ 1520-0477(1999)080<0029:AOOTRO > 2.0.CO;2.

Gimeno, L., 2014: Oceanic sources of continental precipitation. Water Resour. Res., 50, 3647-3649, https://doi.org/10.1002/ 2014WR015477.

Han, T., H. Chen, and H. Wang, 2015: Recent changes in summer precipitation in Northeast China and the background circulation. Int. J. Climatol., 35, 4210-4219, https://doi.org/10.1002/ joc. 4280 .

Hiyama, T., H. Fujinami, H. Kanamori, T. Ishige, and K. Oshima, 2016: Recent interdecadal changes in the interannual variability of precipitation and atmospheric circulation over northern Eurasia. Environ. Res. Lett., 11, 065001, https:// doi.org/10.1088/1748-9326/11/6/065001.

Ho, C. H., J. Y. Lee, M. H. Ahn, and H. S. Lee, 2003: A sudden change in summer rainfall characteristics in Korea during the late 1970s. Int. J. Climatol., 23, 117-128, https://doi.org/10.1002/joc.864.

IPCC, 2013: Climate Change 2013: The Physical Science Basis. Cambridge University Press, 1535 pp., https://doi.org/10.1017/ CBO9781107415324.

Iwao, K., and M. Takahashi, 2006: Interannual change in summertime precipitation over northeast Asia. Geophys. Res. Lett., 33, L16703, https://doi.org/10.1029/2006GL027119.

$\longrightarrow$, and —, 2008: A precipitation seesaw mode between northeast Asia and Siberia in summer caused by Rossby waves over the Eurasian continent. J. Climate, 21, 2401-2419, https:// doi.org/10.1175/2007JCLI1949.1.

Joussaume, S., and R. Sadourny, 1986: Origin of precipitating water in a numerical simulation of the July climate. Ocean-Air Interact., 1, 43-56.

Kerr, R. A., 2000: A North Atlantic climate pacemaker for the centuries. Science, 288, 1984-1985, https://doi.org/10.1126/ science.288.5473.1984.

Khon, V. C., I. Mokhov, E. Roeckner, and V. Semenov, 2007: Regional changes of precipitation characteristics in northern Eurasia from simulations with global climate model. Global Planet. Change, 57, 118-123, https://doi.org/10.1016/ j.gloplacha.2006.11.006.

Koster, R., J. Jouzel, R. Suozzo, and G. Russell, 1986: Global sources of local precipitation as determined by the NASA/GISS GCM. Geophys. Res. Lett., 13, 121-124, https://doi.org/10.1029/ GL013i002p00121.

Kushnir, Y., 1994: Interdecadal variations in North Atlantic sea surface temperature and associated atmospheric conditions. 
J. Climate, 7, 141-157, https://doi.org/10.1175/1520-0442(1994) 007<0141:IVINAS $>2.0$. CO;2.

Lee, E.-J., J.-G. Jhun, and C.-K. Park, 2005: Remote connection of the northeast Asian summer rainfall variation revealed by a newly defined monsoon index. J. Climate, 18, 4381-4393, https://doi.org/10.1175/JCLI3545.1.

Li, X., S.-P. Xie, S. T. Gille, and C. Yoo, 2016: Atlantic-induced pan-tropical climate change over the past three decades. Nat. Climate Change, 6, 275-279, https://doi.org/10.1038/ nclimate2840.

Li, Y., Y. Ding, and W. Li, 2017: Interdecadal variability of the Afro-Asian summer monsoon system. Adv. Atmos. Sci., 34, 833-846, https://doi.org/10.1007/s00376-017-6247-7.

Lin, S.-J., 2004: A “vertically Lagrangian” finite-volume dynamical core for global models. Mon. Wea. Rev., 132, 2293-2307, https://doi.org/10.1175/1520-0493(2004)132<2293:AVLFDC >2.0. $\mathrm{CO} ; 2$.

McGregor, S., A. Timmermann, M. F. Stuecker, M. H. England, M. Merrifield, F.-F. Jin, and Y. Chikamoto, 2014: Recent Walker circulation strengthening and Pacific cooling amplified by Atlantic warming. Nat. Climate Change, 4, 888-892, https:// doi.org/10.1038/nclimate2330.

Munkhtsetseg, E., R. Kimura, J. Wang, and M. Shinoda, 2007: Pasture yield response to precipitation and high temperature in Mongolia. J. Arid Environ., 70, 94-110, https://doi.org/ 10.1016/j.jaridenv.2006.11.013.

Noone, D., and I. Simmonds, 2002: Annular variations in moisture transport mechanisms and the abundance of $\delta^{18} \mathrm{O}$ in Antarctic snow. J. Geophys. Res., 107, 4742, https://doi.org/10.1029/ 2002JD002262.

Numaguti, A., 1999: Origin and recycling processes of precipitating water over the Eurasian continent: Experiments using an atmospheric general circulation model. J. Geophys. Res., 104, 1957-1972, https://doi.org/10.1029/1998JD200026.

Orth, R., and S. I. Seneviratne, 2017: Variability of soil moisture and sea surface temperatures similarly important for warm-season land climate in the Community Earth System Model. J. Climate, 30, 2141-2162, https://doi.org/10.1175/JCLI-D-15-0567.1.

Park, J.-H., L. Duan, B. Kim, M. J. Mitchell, and H. Shibata, 2010: Potential effects of climate change and variability on watershed biogeochemical processes and water quality in northeast Asia. Environ. Int., 36, 212-225, https://doi.org/10.1016/j.envint.2009. 10.008 .

Pausata, F. S. R., D. S. Battisti, K. H. Nisancioglu, and C. M. Bitz, 2011: Chinese stalagmite $\delta^{18} \mathrm{O}$ controlled by changes in the Indian monsoon during a simulated Heinrich event. Nat. Geosci., 4, 474-480, https://doi.org/10.1038/ngeo1169.

Peterson, W. T., and F. B. Schwing, 2003: A new climate regime in northeast Pacific ecosystems. Geophys. Res. Lett., 30, 1896, https://doi.org/10.1029/2003GL017528.

Piao, J., W. Chen, K. Wei, Y. Liu, H.-F. Graf, J.-B. Ahn, and A. Pogoreltsev, 2017: An abrupt rainfall decrease over the Asian inland plateau region around 1999 and the possible underlying mechanism. Adv. Atmos. Sci., 34, 456-468, https:// doi.org/10.1007/s00376-016-6136-5.

— - — , Q. Zhang, and P. Hu, 2018: Comparison of moisture transport between Siberia and northeast Asia on annual and interannual time scales. J. Climate, 31, 7645-7660, https:// doi.org/10.1175/JCLI-D-17-0763.1.

Qian, C., J.-Y. Yu, and G. Chen, 2014: Decadal summer drought frequency in China: The increasing influence of the Atlantic multi-decadal oscillation. Environ. Res. Lett., 9, 124004, https://doi.org/10.1088/1748-9326/9/12/124004.
Rasch, P., and J. Kristjánsson, 1998: A comparison of the CCM3 model climate using diagnosed and predicted condensate parameterizations. J. Climate, 11, 1587-1614, https://doi.org/ 10.1175/1520-0442(1998)011<1587:ACOTCM > 2.0.CO;2.

Rayner, N., D. E. Parker, E. B. Horton, C. K. Folland, L. V. Alexander, D. P. Rowell, E. C. Kent, and A. Kaplan, 2003: Global analyses of sea surface temperature, sea ice, and night marine air temperature since the late nineteenth century. J. Geophys. Res., 108, 4407, https://doi.org/10.1029/2002 JD002670.

Rodell, M., and Coauthors, 2004: The Global Land Data Assimilation System. Bull. Amer. Meteor. Soc., 85, 381-394, https://doi.org/ 10.1175/BAMS-85-3-381.

Salih, A. A. M., Q. Zhang, F. S. R. Pausata, and M. Tjernstrom, 2016: Sources of Sahelian-Sudan moisture: Insights from a moisture-tracing atmospheric model. J. Geophys. Res. Atmos., 121, 7819-7832, https://doi.org/10.1002/2015JD024575.

Sato, T., and T. Nakamura, 2019: Intensification of hot Eurasian summers by climate change and land-atmosphere interactions. Sci. Rep., 9, 10866, https://doi.org/10.1038/s41598-01947291-5.

— Asia as revealed by field observations and isotope transport model. J. Geophys. Res., 112, D17112, https://doi.org/10.1029/ 2006JD008321.

Schlesinger, M. E., and N. Ramankutty, 1994: An oscillation in the global climate system of period 65-70 years. Nature, $\mathbf{3 6 7}, 723$ 726, https://doi.org/10.1038/367723a0.

Serreze, M. C., and A. J. Etringer, 2003: Precipitation characteristics of the Eurasian Arctic drainage system. Int. J. Climatol., 23, 1267-1291, https://doi.org/10.1002/joc.941.

Sodemann, H., H. Wernli, and C. Schwierz, 2009: Sources of water vapour contributing to the Elbe flood in August 2002-A tagging study in a mesoscale model. Quart. J. Roy. Meteor. Soc., 135, 205-223, https://doi.org/10.1002/qj.374.

Sun, L., B. Shen, Z. Gao, B. Sui, L. Bai, S.-H. Wang, G. An, and J. Li, 2007: The impacts of moisture transport of East Asian monsoon on summer precipitation in northeast China. $A d v$. Atmos. Sci., 24, 606-618, https://doi.org/10.1007/s00376-0070606-8.

,-- , and B. Sui, 2010: A study on water vapor transport and budget of heavy rain in northeast China. Adv. Atmos. Sci., 27, 1399-1414, https://doi.org/10.1007/s00376-010-9087-2.

Sutton, R. T., and B. Dong, 2012: Atlantic Ocean influence on a shift in European climate in the 1990s. Nat. Geosci., 5, 788792, https://doi.org/10.1038/ngeo1595.

Trenberth, K. E., 1991: Climate diagnostics from global analyses: Conservation of mass in ECMWF analyses. J. Climate, 4, 707722, https://doi.org/10.1175/1520-0442(1991)004<0707:CDFGAC > 2.0.CO;2.

- 1998: Atmospheric moisture residence times and cycling: Implications for rainfall rates with climate change. Climatic Change, 39, 667-694, https://doi.org/10.1023/A:1005319109110.

— A. Dai, R. M. Rasmussen, and D. B. Parsons, 2003: The changing character of precipitation. Bull. Amer. Meteor. Soc., 84, 1205-1218, https://doi.org/10.1175/BAMS-84-9-1205.

Van der Ent, R. J., and H. H. G. Savenije, 2013: Oceanic sources of continental precipitation and the correlation with sea surface temperature. Water Resour. Res., 49, 3993-4004, https:// doi.org/10.1002/wrcr.20296.

Wang, H., and S. He, 2015: The north China/northeastern Asia severe summer drought in 2014. J. Climate, 28, 6667-6681, https://doi.org/10.1175/JCLI-D-15-0202.1. 
Wang, L., Z. Wu, H. He, F. Wang, H. Du, and S. Zong, 2017: Changes in summer extreme precipitation in northeast Asia and their relationships with the East Asian summer monsoon during 1961-2009. Int. J. Climatol., 37, 25-35, https://doi.org/ 10.1002/joc. 4683 .

Werner, M., M. Heimann, and G. Hoffmann, 2001: Isotopic composition and origin of polar precipitation in present and glacial climate simulations. Tellus, 53B, 53-71, https://doi.org/ 10.3402/tellusb.v53i1.16539.

Williamson, D. L., 2002: Time-split versus process-split coupling of parameterizations and dynamical core. Mon. Wea. Rev., 130, 2024-2041, https://doi.org/10.1175/1520-0493(2002)130<2024: TSVPSC $>2.0 . \mathrm{CO} ; 2$.

Xu, K.-M., and S. K. Krueger, 1991: Evaluation of cloudiness parameterizations using a cumulus ensemble model. Mon. Wea. Rev., 119, 342-367, https://doi.org/10.1175/1520-0493(1991) $119<0342$ :EOCPUA $>2.0 . \mathrm{CO} ; 2$

$\mathrm{Xu}, \mathrm{Z}$., K. Fan, and H. Wang, 2015: Decadal variation of summer precipitation over China and associated atmospheric circulation after the late 1990s. J. Climate, 28, 4086-4106, https:// doi.org/10.1175/JCLI-D-14-00464.1.

Yatagai, A., and T. Yasunari, 1998: Variation of summer water vapor transport related to precipitation over and around the arid region in the interior of the Eurasian continent. J. Meteor. Soc. Japan, 76, 799-815, https://doi.org/10.2151/jmsj1965.76.5_799.

Ye, H., E. J. Fetzer, S. Wong, A. Behrangi, E. T. Olsen, J. Cohen, B. H. Lambrigtsen, and L. Chen, 2014: Impact of increased water vapor on precipitation efficiency over northern Eurasia. Geophys. Res. Lett., 41, 2941-2947, https://doi.org/10.1002/ 2014GL059830.

Yu, L., and R. A. Weller, 2007: Objectively analyzed air-sea heat fluxes for the global ice-free oceans (1981-2005). Bull. Amer. Meteor. Soc., 88, 527-540, https://doi.org/10.1175/BAMS-88-4527.
Zhang, C., Q. Tang, D. Chen, R. J. Ent, X. Liu, W. Li, and G. G. Haile, 2019: Moisture source changes contributed to different precipitation changes over the northern and southern Tibetan Plateau. J. Hydrometeor., 20, 217-229, https://doi.org/10.1175/ JHM-D-18-0094.1.

Zhang, M., W. Lin, C. S. Bretherton, J. J. Hack, and P. J. Rasch, 2003: A modified formulation of fractional stratiform condensation rate in the NCAR Community Atmospheric Model (CAM2). J. Geophys. Res., 108, 4035, https://doi.org/10.1029/ 2002JD002523.

Zhang, X., J. He, J. Zhang, I. Polyakov, R. Gerdes, J. Inoue, and $\mathrm{P}$. $\mathrm{Wu}, 2013$ : Enhanced poleward moisture transport and amplified northern high-latitude wetting trend. Nat. Climate Change, 3, 47-51, https://doi.org/10.1038/nclimate1631.

Zhang, Z., X. Sun, and X.-Q. Yang, 2018: Understanding the interdecadal variability of East Asian summer monsoon precipitation: Joint influence of three oceanic signals. J. Climate, 31, 5485-5506, https://doi.org/10.1175/JCLI-D-17-0657.1.

Zhao, W., S. Chen, W. Chen, S. Yao, D. Nath, and B. Yu, 2019: Interannual variations of the rainy season withdrawal of the monsoon transitional zone in China. Climate Dyn., 53, 20312046, https://doi.org/10.1007/s00382-019-04762-9.

Zhou, T. J., and R. C. Yu, 2005: Atmospheric water vapor transport associated with typical anomalous summer rainfall patterns in China. J. Geophys. Res., 110, D08104, https://doi.org/10.1029/ 2004JD005413.

Zhu, C., B. Wang, W. Qian, and B. Zhang, 2012: Recent weakening of northern East Asian summer monsoon: A possible response to global warming. Geophys. Res. Lett., 39, L09701, https:// doi.org/10.1029/2012GL051155.

Zhu, Y., H. Wang, W. Zhou, and J. Ma, 2011: Recent changes in the summer precipitation pattern in East China and the background circulation. Climate Dyn., 36, 1463-1473, https:// doi.org/10.1007/s00382-010-0852-9. 